Document downloaded from:

http://hdl.handle.net/10251/82709

This paper must be cited as:

Ruiz Calvo, F.; De Rosa, M.; Monzó Cárcel, PM.; Montagud Montalvá, Cl.; Corberán Salvador, JM. (2016). Coupling short-term (B2G model) and long-term (g-function) models for ground source heat exchanger simulation in TRNSYS. Application in a real installation. Applied Thermal Engineering. 102:720-732. doi:10.1016/j.applthermaleng.2016.03.127.

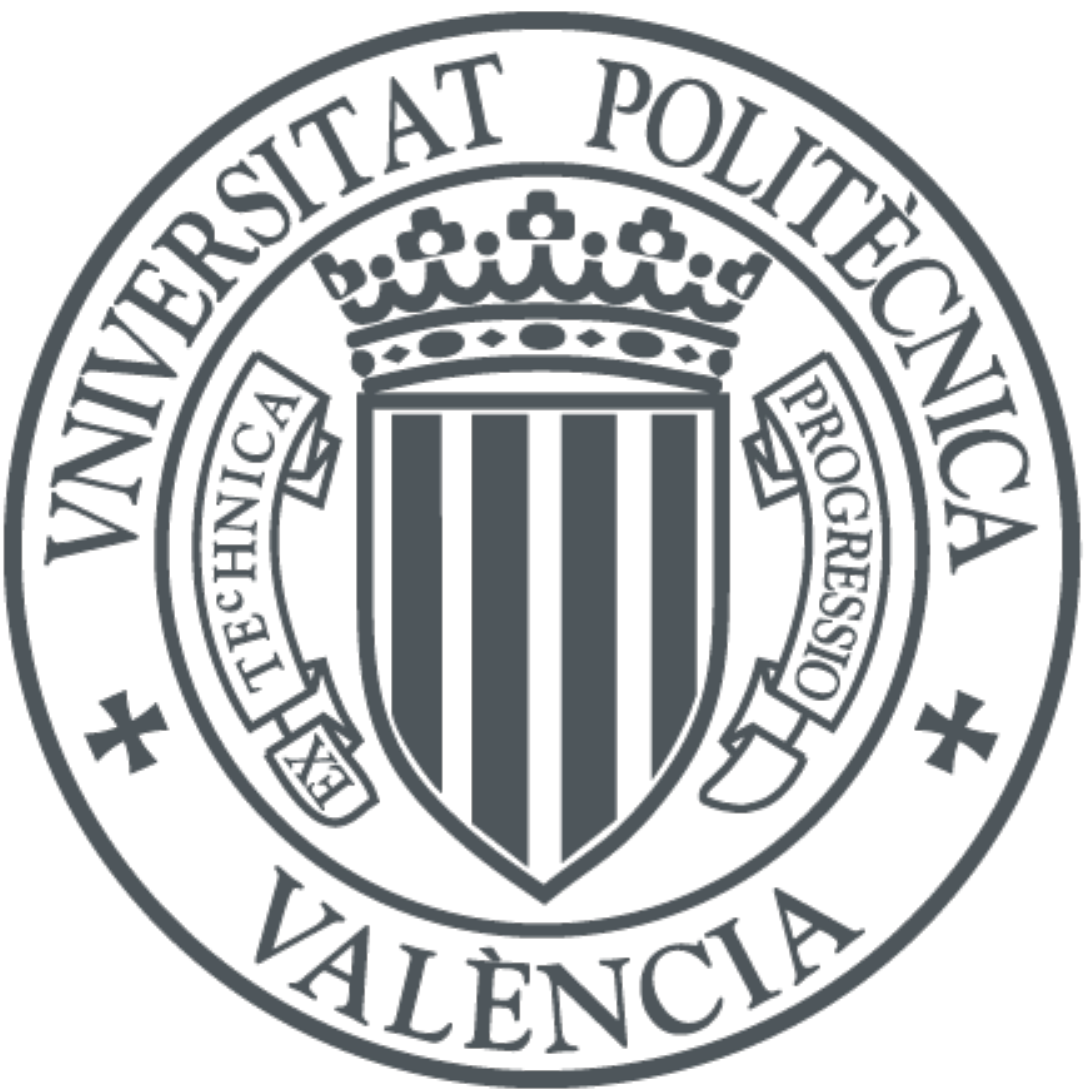

The final publication is available at

http://doi.org/10.1016/j.applthermaleng.2016.03.127

Copyright Elsevier

Additional Information 
Thermal Engineering

Elsevier Editorial System(tm) for Applied

Manuscript Draft

Manuscript Number: ATE-2015-10963R1

Title: Coupling short-term (B2G model) and long-term (g-function) models for ground source heat exchanger simulation in TRNSYS. Application in a real installation

Article Type: Research Paper

Keywords: ground source heat pump; borehole heat exchanger; heating and cooling systems; dynamic modeling

Corresponding Author: Dr. Carla Montagud,

Corresponding Author's Institution: IIE

First Author: Félix Ruiz-Calvo

Order of Authors: Félix Ruiz-Calvo; Mattia De Rosa; Patricia Monzó; Carla Montagud; José Miguel Corberán

Abstract: Ground-source heat pump (GSHP) systems represent one of the most promising techniques for heating and cooling in buildings. These systems use the ground as a heat source/sink, allowing a better efficiency thanks to the low variations of the ground temperature along the seasons. The ground-source heat exchanger (GSHE) then becomes a key component for optimizing the overall performance of the system. Moreover, the short-term response related to the dynamic behaviour of the GSHE is a crucial aspect, especially from a regulation criteria perspective in on/off controlled GSHP systems. In this context, a novel numerical GSHE model has been developed at the Instituto de Ingeniería Energética, Universitat Politècnica de València. Based on the decoupling of the short-term and the long-term response of the GSHE, the novel model allows the use of faster and more precise models on both sides. In particular, the short-term model considered is the B2G model, developed and validated in previous research works conducted at the Instituto de Ingeniería Energética. For the long-term, the g-function model was selected, since it is a previously validated and widely used model, and presents some interesting features that are useful for its combination with the B2G model. The aim of the present paper is to describe the procedure of combining these two models in order to obtain a unique complete GSHE model for both short- and long-term simulation. The resulting model is then validated against experimental data from a real GSHP installation. 
Dear reviewers,

Thank you for taking the time to review the paper and for your comments and suggestions. It has been very positive to improve the paper. We hope that we have satisfactorily answered your questions and now you will find the paper acceptable for publication. The corrections have been indicated in blue color in the reviewed version of the manuscript.

Please find below our response to your comments/suggestions:

Reviewer \#1: This is a very interesting paper. I have only a few minor suggestions

1. The abstract should be shortened. The middle section could be much shorter.

Ok, it has been shortened accordingly.

2. You use GHSE and GSHE in the abstract?

Sorry, actually this was a typo. It should be used always as GSHE. It has been corrected.

3. line 21. To talk about 'on a steady-state basis' and then g-function models is not consistent. It is not true to say many models focus on the steady-state. You need to be more specific/accurate.

Yes, you are totally right. We have provided a more accurate explanation in the text.

4. Figure 8. Shouldn't the g-function approach zero or slightly negative on the left?

Thank you for your comment.

The g-function represents the temperature drop at the borehole wall in relation to its undisturbed ground temperature when a total constant heat flux is imposed in the bore field.

$$
T_{b w}(t)-T_{g}=\frac{q}{2 \pi \lambda} * g\left(\frac{t}{t_{s}}, \frac{r_{b}}{H}, \frac{B}{H}, \frac{D}{H}\right)
$$

For $t>\theta$ and a constant heat flux rejection $(q>\theta)$, and $\left(t>5 r_{b} / \alpha\right.$ which results in $t>10.98$ hours for the characteristics of the UPV bore field), the g-function values are illustrated in the following table:

\begin{tabular}{|l|l|l|}
\hline Time & Ln 9FoH & g-function value \\
\hline 11 hours & -9.09 & 1.234 \\
\hline 20.98 hours & -8.45 & 1.546 \\
\hline 32.85 hours & -8.00 & 1.752 \\
\hline
\end{tabular}

The g-function will be equal to zero at time $t=0$. The g-function will not reach negative values.

Reviewer \#2: In equations (1) to (5) the thermal capacitance must be used instead of the volumetric thermal capacitance. The symbol for velocity in 
equation (1) and (2) cannot be found in the nomenclature. Index $f$ is not defined in nomenclature.

Yes, you are totally right. It was a typo. It has been corrected accordingly in the equations and the index ' $f$ ' which stands for the fluid inside the U-pipe has been defined in the nomenclature. And the symbol for velocity has been added accordingly in the nomenclature.

In equation (7) the average heat flow per unit borehole length is called $\mathrm{q}$ but cannot be found in the nomenclature. In equation (7) the thermal load $\mathrm{q}$-dot has to be used.

Yes, you are totally right. Equation (7) has been corrected accordingly, as well as the nomenclature $\rightarrow$ q_dot will stand for the thermal load per unit borehole length expressed in $(\mathrm{W} / \mathrm{m})$. On the other hand, Figures $3,4,5$ and 9 have also been corrected, (the units have been extracted as there was no need to include them for the figure) in order to be consistent with the correction in the nomenclature.

The boundary conditions of the experimental studies (ambient temperature, air-conditioned building area, control strategy) are not clear and should be completed.

Ok, a paragraph explaining this has been added in the description of the installation.

The paper should be revised concerning grammatical issues, especially the references and the nomenclature should be kept consistently in terms of case sensitivity.

Ok, the whole paper has been reviewed accordingly.

Subscripts and indices should be written non-cursive.

Ok, it has been corrected accordingly.

The data given in table 2 are not clear: what is I in fig. 7?

Thank you for pointing out this issue.

In this paper, "I" refers to the inactive upper part of the borehole (shank +freatic level), which is about $3.5 \mathrm{~m}$. This geometrical parameter was defined as "D" when g-function was introduced by Eskilson. In the present study, "D" makes reference to the diameter. In order to better clarifiy it, Figure 7 has been updated with a detailed drawing of the geometrical parameters involved in the g-function definition according to the nomenclature used in this work. 


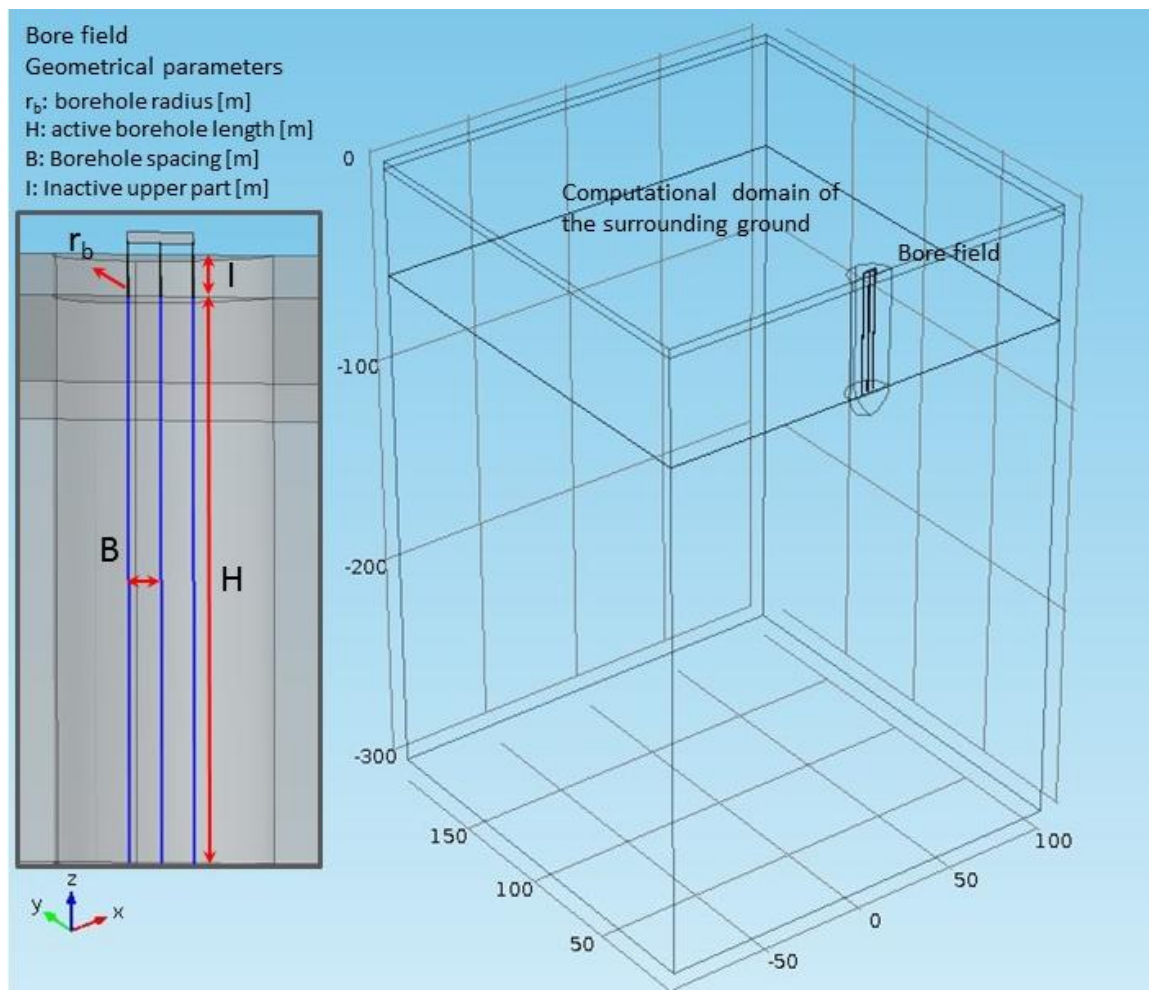

In table 4 it is not clear, that the absolute error is related to the temperature.

Ok, it has been better clarified in the table caption and in the table itself.

The description of the GeoCool Plant as well as the description of the geothermal field can be shortened to the main aspects related to the current studies. On the other hand, the air-conditioning strategy of the air-conditioned room is not clear, but would be an interesting boundary condition of the experimental studies.

Ok, the description has been shortened accordingly. The following sentence has been added 'Further information can be found in [35] and [36]'. Finally, some more information has been added regarding the airconditioning strategy of the air-conditioned room in the description of the installation.

Related measurement uncertainties of the different sensors installed in the experimental GSHP installation could be provided more clearly in a table.

Ok, the text where they were presented has been erased and a new table (Table 2) has been created instead. The rest of the tables have been renumbered accordingly.

Some pictures are not readable in black \& white print, for example fig. 11.

Ok, the format has been corrected accordingly in Figure 11. For the rest of the figures, the colors were specially chosen so that they were readable when printing in black on white. We hope that now it is acceptable for publication. 


\section{Highlights:}

- A novel dynamic Borehole Heat Exchanger model is presented.

- The B2G dynamic model is coupled to the g-function steady state model.

- The complete GSHE model has been programmed in TRNSYS.

- Model performance has been validated against experimental data. 


\title{
Coupling short-term (B2G model) and long-term (g-function) models for ground source heat exchanger simulation in TRNSYS. Application in a real installation
}

\author{
Félix Ruiz-Calvo ${ }^{a}$, Mattia De Rosa ${ }^{b}$, Patricia Monzóc ${ }^{c}$ Carla Montagud ${ }^{a^{*}}$, \\ José M. Corberán ${ }^{a}$ \\ a Instituto de Ingeniería Energética, Universitat Politècnica de València. \\ Camino de Vera sn 46022 Valencia, Spain. Phone: +34-96-3879910. Fax: \\ +34-963877272.carmonmo@iie.upv.es

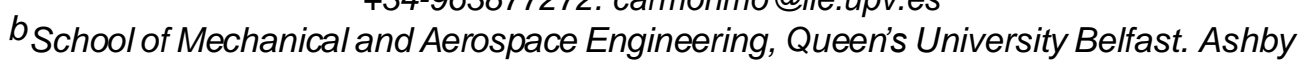 \\ Building, Stranmillis Road. BT9 5AG, Belfast (UK) \\ ${ }^{C_{E}}$ Energy Technology Department, KTH Royal Institute of Technology, Brinellvägen 68, \\ 10044 Stockholm, Sweden
}

\begin{abstract}
Ground-source heat pump (GSHP) systems represent one of the most promising techniques for heating and cooling in buildings. These systems use the ground as a heat source/sink, allowing a better efficiency thanks to the low variations of the ground temperature along the seasons. The ground-source heat exchanger (GSHE) then becomes a key component for optimizing the overall performance of the system. Moreover, the short-term response related to the dynamic behaviour of the GSHE is a crucial aspect, especially from a regulation criteria perspective in on/off controlled GSHP systems. In this context, a novel numerical GSHE model has been developed at the Instituto de Ingeniería Energética, Universitat Politècnica de València. Based on the decoupling of the short-term and the long-term response of the GSHE, the novel model allows the use of faster and more precise models on both sides. In particular, the shortterm model considered is the B2G model, developed and validated in previous research works conducted at the Instituto de Ingeniería Energética. For the longterm, the g-function model was selected, since it is a previously validated and widely used model, and presents some interesting features that are useful for its combination with the B2G model. The aim of the present paper is to describe the procedure of combining these two models in order to obtain a unique complete GSHE model for both short- and long-term simulation. The resulting model is then validated against experimental data from a real GSHP installation.
\end{abstract}

Keywords: ground source heat pump, borehole heat exchanger, heating and cooling systems, dynamic modeling 


\section{Introduction}

Among the currently available options for heating and cooling systems, ground source heat pump (GSHP) systems are one of the most efficient and comfortable [1]. The main advantage of these systems consists of using the ground as a heat source/sink, depending on the operating mode, which provides a more stable temperature than air. Therefore, GSHP systems present a higher efficiency than the conventional air-to-water heat pump systems [2].

The heat exchange with the ground takes place in the ground source heat exchanger (GSHE), usually by means of a certain number of borehole heat exchangers (BHE) that are drilled in the ground. So, the GSHE becomes a key component of the system, and the focus of many research works aims at improving the system's energy performance $([3,4])$.

In this context, an accurate model of the GSHE can be very useful in order to study the different configurations for this component and how it affects the global thermal efficiency. There are several approaches that can be considered when modelling a GSHE. An accurate review of the different models currently available is presented in [5]. Among them, the ones discussed in the following will be focused on one of the most common BHE configurations: vertical boreholes with $U$ tubes.

Many of the most widespread GSHE models are mainly focused on modelling the behaviour of the ground surrounding the boreholes for long-term time scales. The g-function model, proposed by Eskilson [6], is one of the most widely used. This model is based on the use of non-dimensional temperature response functions ( $\mathrm{g}$-functions) representing the evolution of the temperature at the BHE wall for a constant heat injection pulse. In [7], the original g-functions are extended to shorter time steps of one hour. This model has been used both in simulation and design software such as GLHEPRO [8] and EED [9]. Along the years, the g-function model has been continuously improved in different ways (e.g., [10, 11]). In order to take into account the transient behaviour, Beier [12] developed an analytical model by coupling transient heat conduction equations for both grout and ground with the energy equations for the circulating fluid in each pipe. The transient solution, obtained by means of Laplace transform, gives an estimation of the ground thermal conductivity and borehole resistance with a reasonable accuracy.

Another of the most commonly used approaches for BHE modelling 
corresponds to the thermal network models. In this kind of models, the borehole and its surrounding are represented by a series of temperature nodes, connected by thermal resistances. It is possible to include the thermal inertia of the materials in the model by means of thermal capacitances connected to the temperature nodes. The standard delta network (Figure 1, [13]) has been successively improved, usually adding more nodes to the network, as in $[14,15,16]$ or depending on the borehole geometries [17]. With the thermal network model, it is possible to obtain a high accuracy on the simulation of the BHE behaviour, but it usually requires a high number of nodes in order to correctly represent the ground and the interaction between boreholes. This results in an increase in the number of differential equations to solve, which leads to a higher computational cost.

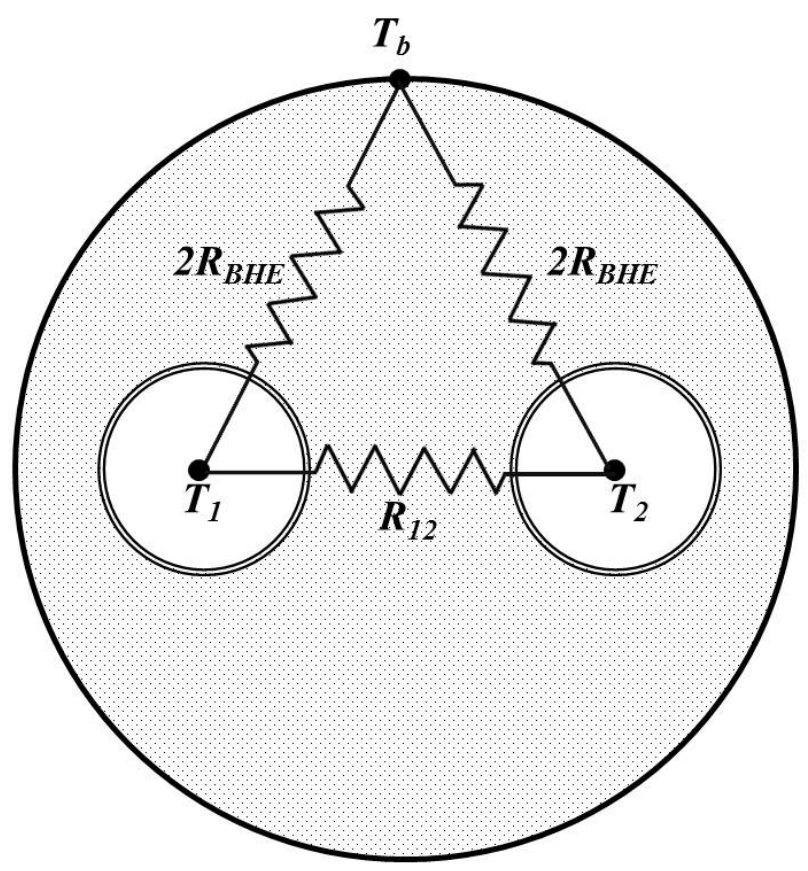

Figure 1: Standard steady state delta network [13].

Finally, the finite elements model (FEM) is one of the most detailed models currently available $[18,19,20,21,22,23]$. This model uses a very fine discretization of the BHE, which produces the most accurate results, although having a very high computational cost. FEM models are usually used as a reference for validation of simpler models able to provide faster simulations, even if they are not so accurate.

Other numerical models have been developed in the recent years, 
adopting different approaches [24, 25, 26, 27]. Usually, they can only be used for long-term calculations. However, the dynamic behaviour of the BHE in the short-term response can be a relevant issue, since the GSHEs are usually integrated in other systems (such as GSHP systems), where the short-term control algorithms have a high influence in the performance of the whole system.

A complete model of a GSHP installation, located at Universitat Politècnica de València (UPV), has been recently developed by the authors [28, 29]. In this installation, the operation of the system is governed by an on/off algorithm, which controls the switching of the heat pump and the external circulation pump. In a typical operation day, the total time that the installation is working is around $15 \mathrm{~h}$, while the total time of heat injection/extraction in the GSHE varies depending on the thermal load, taking values up to $10 \mathrm{~h}$. However, the heat pulses corresponding to the time that the heat pump is switched on have a duration of about 10 minutes, also depending on the instantaneous thermal load. This kind of control results in a characteristic evolution on the temperatures of the water circulating through the GSHE, which is very influenced by the dynamic behaviour of the BHEs. Therefore, a GSHE model able to reproduce the instantaneous response due to the HP control is required. Moreover, its computational efficiency is a relevant issue, since the GSHE model has to be coupled with models of other system components, in order to obtain a unique tool able to simulate the whole system.

In this paper, a new GSHE model is presented, based on the decoupling of the short-term and the long-term responses of the BHEs. Thanks to this approach, it is possible to use faster and more precise models on both sides, combining them afterwards to form a complete GSHE model. For the short-time model, a novel model based on the thermal network approach has been developed, called B2G model. The B2G model has been previously validated against experimental data corresponding to BHEs located at Stockholm [30] and Valencia [31]. This model has proven to be able to correctly predict the behaviour of the fluid temperatures exiting the borehole for heat injection/extraction times up to 10 hours, while keeping a very accurate prediction of the instantaneous response as well. For the long-term, the g-function model has been selected, since it is a previously validated and widely used model, presenting several interesting characteristics that are useful for its combination with the B2G model.

The aim of this paper is to describe these two models and the procedure to combine them in order to obtain a complete model of a GSHE system. 
The resulting tool has been validated against experimental data collected from the GSHE system located at the Universitat Politècnica de València.

\section{GSHE model}

As introduced before, most of the currently available models are focused on long-term response simulations, while models able to predict the BHE short-term behaviour are usually based on FEM techniques, with consequent high computational costs. Generally, it is difficult to obtain a model which is useful for modelling both short-term and long-term behavior and which maintains a computational cost low enough to combine the BHE model with other component ones.

In order to achieve this goal, a novel numerical model, based on decoupling the long-term and short-term simulation, is presented. This decoupling allows the use of faster models on each side: the short-term model only takes into account the local heat transfer between the fluid flow, the borehole and its adjacent piece of ground, while the long-term model is able to calculate the initial ground temperature for each day, taking into account the thermal load injected/extracted in the GSHE during the previous day. This approach should reduce the total computational cost of the whole model, since it is not necessary to calculate the long-term response of the ground at each time-step.

\subsection{Short-term response: B2G model}

The short-term evolution of the fluid temperature depends on the grout temperature and on the portion of the ground closer to the BHE. Knowing the thermo-physical properties of both grout and ground, it is possible to develop a numerical model which takes into account their dynamic response. Considering the GSHP typical operation, the short-term model should be able to reproduce the instantaneous performance of the BHE during the daily heat injection/extraction times up to 10 hours in an on/off operating control criteria, starting from the initial ground temperature of each day.

Following this purpose, a short-term BHE dynamic model, called Borehole- to-Ground (B2G) model, was developed at the Instituto de Ingeniería Energética (IIE) - Universitat Politècnica de València. B2G model was firstly presented and validated against different experimental data in [30] and [31]. In the present section, a brief description of the model is provided as an introduction to the further development presented in the current paper. More information about the B2G shortterm model can be found in $[30,31]$. 


\subsubsection{Model equations}

The B2G short-term model is based on the delta network model coupled to the lumped thermal capacitance approach. Starting from the work carried out by Bauer et al. [14, 15], a vertical discretization of the borehole is made and, for each node, a thermal network describes the radial heat transfer at each borehole depth (Fig.1a). The thermal network configuration has been chosen in order to ensure a good accuracy of the model predictions while reducing the total number of parameters as much as possible. In particular, the BHE is divided into two separate regions (Fig.1a) according to the shank spacing of the U-tube, as suggested by Lamarche et al. [17]. Therefore, two different grout nodes with a correspondent lumped thermal capacitance can be detected; both grout nodes are interconnected by a thermal resistance $R_{\mathrm{bb}}$, and to a unique ground node by the resistance $R_{g}$, resulting in a delta-network different from the standard delta-network [6].

Neglecting the vertical heat conduction, the resulting thermal network consists of five thermal capacitances and six thermal resistances at each depth layer of the borehole heat exchanger, building a 5C6R-n model (where $\mathrm{n}$ is the number of the discretization nodes), as shown in Figure1b.

a)

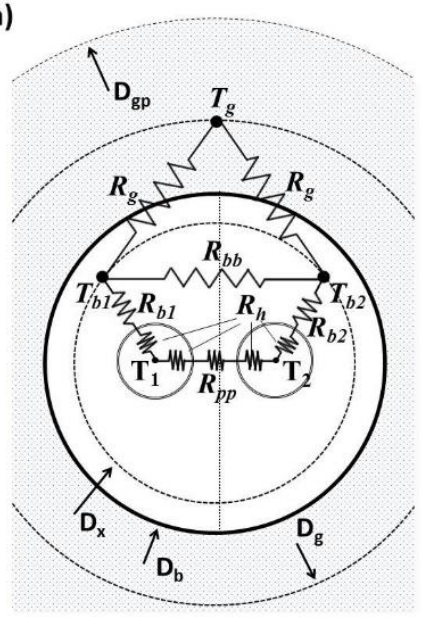

b)

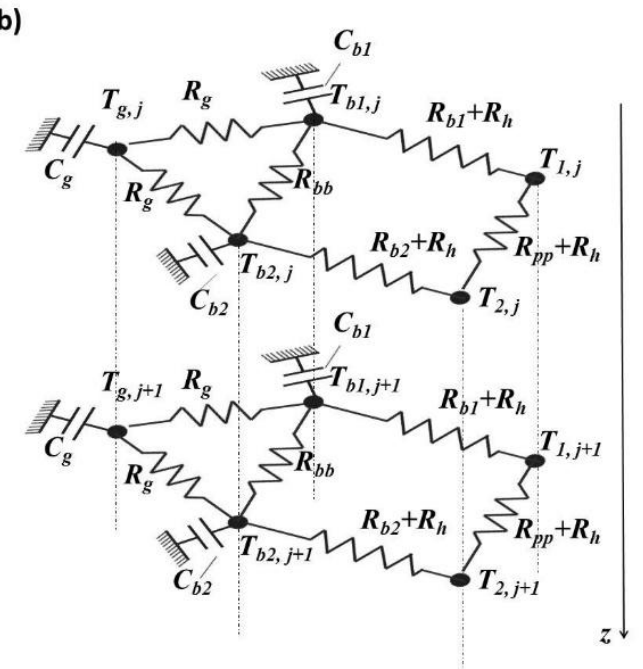

Figure 2: Thermal network model: a) 2D model; b) 3D model [30].

Consequently, the energy balance equations for each node type can be written as shown in Table 1. As it is possible to note, in Eq.1-2, the fluid energy balance equations take into account the advection, which is fundamental to obtain the correct short-term response of the BHE. 


\begin{tabular}{|c|c|c|}
\hline Node & Balance equation & $\begin{array}{l}\text { N. } \\
\text { Eq }\end{array}$ \\
\hline \multirow[t]{2}{*}{$\begin{array}{l}\text { Fluid } \\
\text { Nodes }\end{array}$} & $\frac{\partial T_{1}(z)}{\partial t}=-v \cdot \frac{\partial T_{1}(z)}{\partial t}-\frac{1}{C_{f}}\left(\frac{T_{1}(z)-T_{b 1}(z)}{R_{b 1}}+\frac{T_{1}(z)-T_{2}(z)}{R_{p p}}\right)$ & (1) \\
\hline & $\frac{\partial T_{2}(z)}{\partial t}=-v \cdot \frac{\partial T_{2}(z)}{\partial t}-\frac{1}{C_{f}}\left(\frac{T_{2}(z)-T_{b 2}(z)}{R_{b 2}}-\frac{T_{1}(z)-T_{2}(z)}{R_{p p}}\right)$ & (2) \\
\hline \multirow[t]{2}{*}{$\begin{array}{l}\text { Borehole } \\
\text { Nodes }\end{array}$} & $C_{b 1} \frac{\partial T_{b 1}(z)}{\partial t}=\frac{T_{1}(z)-T_{b 1}(z)}{R_{b 1}}+\frac{T_{b 1}(z)-T_{b 2}(z)}{R_{b b}}-\frac{T_{b 1}(z)-T_{g}(z)}{R_{g}}$ & (3) \\
\hline & $C_{b 2} \frac{\partial T_{b 2}(z)}{\partial t}=\frac{T_{2}(z)-T_{b 2}(z)}{R_{b 2}}-\frac{T_{b 1}(z)-T_{b 2}(z)}{R_{b b}}-\frac{T_{b 2}(z)-T_{g}(z)}{R_{g}}$ & (4) \\
\hline $\begin{array}{l}\text { Ground } \\
\text { Node }\end{array}$ & $C_{g} \frac{\partial T_{g}(z)}{\partial t}=\frac{T_{b 1}(z)-T_{g}(z)}{R_{g}}+\frac{T_{b 2}(z)-T_{g}(z)}{R_{g}}$ & (5) \\
\hline
\end{tabular}

Table 1: B2G energy balance equations [30].

Furthermore, the B2G parameters consist of thermal resistances and capacitances of the different nodes of the thermal network. These parameters can be determined taking into account the borehole geometrical characteristics and thermo-physical properties. The full procedure to determine the values of all the parameters in the thermal network is described in $[30,31]$ and is not reported in the present paper. Despite that, the importance of the ground thermal capacitance calculation needs to be highlighted as it depends on the portion of the ground perturbed by the heat injection and it affects the time horizon of the short-term model. The measure of this effect is the penetration depth $D_{g p}$ which, in turn, depends on the heat injection/extraction time and on the ground thermal diffusivity [6]. For a given penetration depth, the ground thermal capacitance $\mathrm{Cg}$ can be calculated as in the following equation:

$$
C_{g}=\frac{\pi}{4}\left(D_{g p}^{2}-D_{b}^{2}\right) c_{g} d z
$$

In the B2G short-term model, the penetration diameter $D_{g p}$ becomes an adjusting parameter that varies depending on the heat 
injection/extraction duration or, as already said, on the simulated time horizon of the short- term model. A fast way to estimate the penetration diameter $D_{g p}$ is to consider the surrounding ground as a semi-infinite solid subjected to a heat flux for the correspondent period of time. Then, it is possible to solve the heat conduction equation (Fourier diffusion law) taking into account the ground thermo-physical properties. It is important to state that, using the penetration depth for simulation times longer than 18 hours, may produce a losing of accuracy in the instantaneous response, as observed in [30]. 


\subsection{Long-term response: g-function}

Eskilson carried out an extensive study on the thermal response of ground heat exchangers, described in [32, 6]. Eskilson's studies resulted in the introduction of the g-function concept. The $g$-function is a non-dimensional thermal response factor of the borehole wall and the ground outside the borehole under a constant heat load assuming pure heat conduction. The concept can be applied to single boreholes as well as bore fields. The main application of the g-function is the fluid temperature prediction for variable loads by temporal superposition of stepwise constant loads.

For the g-function generation, Eskilson performed several studies regarding the definition of the boundary condition at the borehole wall. Eskilson identified two important boundary conditions: a uniform temperature along the borehole wall or a constant heat load per unit length of the borehole. In both cases, the total heat load is kept constant over time. With boreholes connected in parallel, the common inlet fluid temperature, in combination with a high enough flow rate, would approach the uniform temperature boundary condition, which was also investigated by Eskilson [32]. Thus, the g-function was defined for a uniform temperature condition at the borehole wall. The g-function relates the change of the temperature at the borehole wall $\left(T_{b w}\right)$ over time, from the undisturbed ground temperature $\left(T_{g}\right)$, when a constant average heat flow per unit borehole length $(\dot{q})$ is imposed at the bore field. Equation 7 shows the relation between the borehole wall temperature and the $\mathrm{g}$ function of a bore field located in a given ground with a specified thermal conductivity and heat load. The g-function is specific for the bore field geometry, depending upon its geometrical parameters: $r_{b}, B$ and $I$ expressed as aspect ratios of $H$. The $g$-function is also a function of a non-dimensional time, $\frac{t}{t_{s}}$, where $t_{s}$ is the characteristic time defined as $t_{s}=\frac{H^{2}}{9 \alpha}$.

$$
T_{b w}(t)-T_{g}=\frac{\dot{q}}{2 \pi k} * g\left(\frac{t}{t_{s}}, \frac{r_{b}}{H}, \frac{B}{H}, \frac{I}{H}\right)
$$




\subsubsection{G-function implementation}

In order to correctly represent the real instantaneous thermal load for using it as an input for the g-function, it should be noted that the thermal load has a continuous evolution, while the g-function formulation requires constant load steps as input. Therefore, the thermal load is discretized using constant load blocks with a duration longer than the minimum time resolution of the g-function (Figure 3).

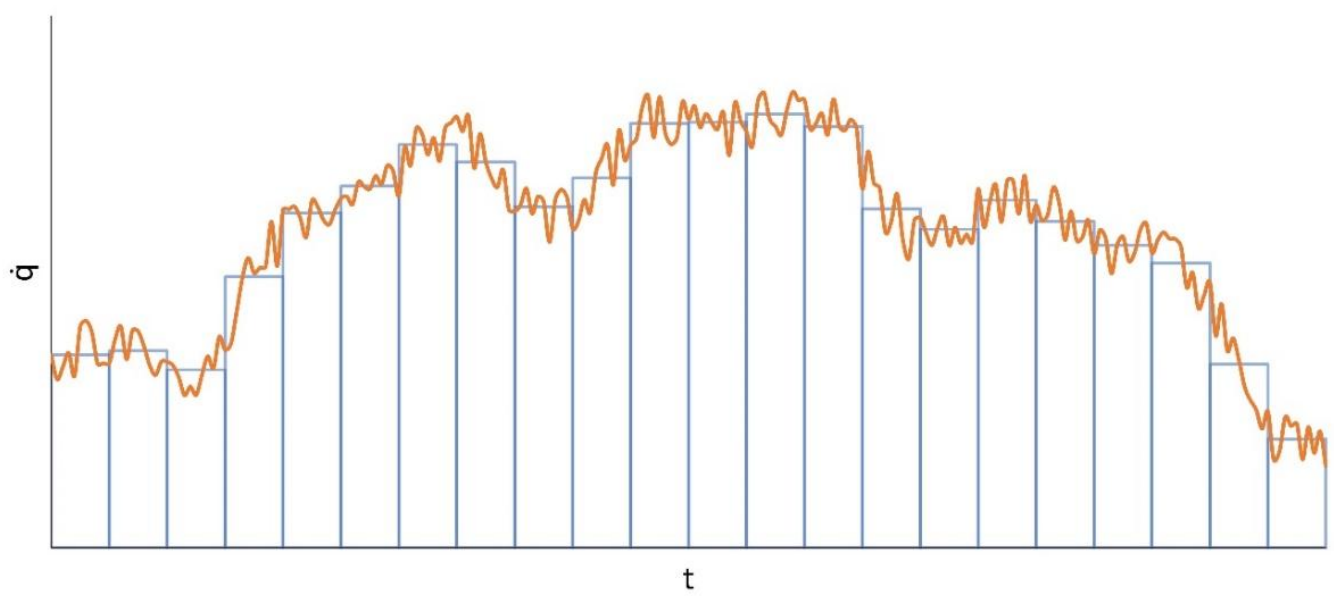

Figure 3: Thermal load blocks representing the evolution of the thermal load [29]

Then, the load blocks can be expressed as a superposition of constant load steps, as shown in Figure 4.

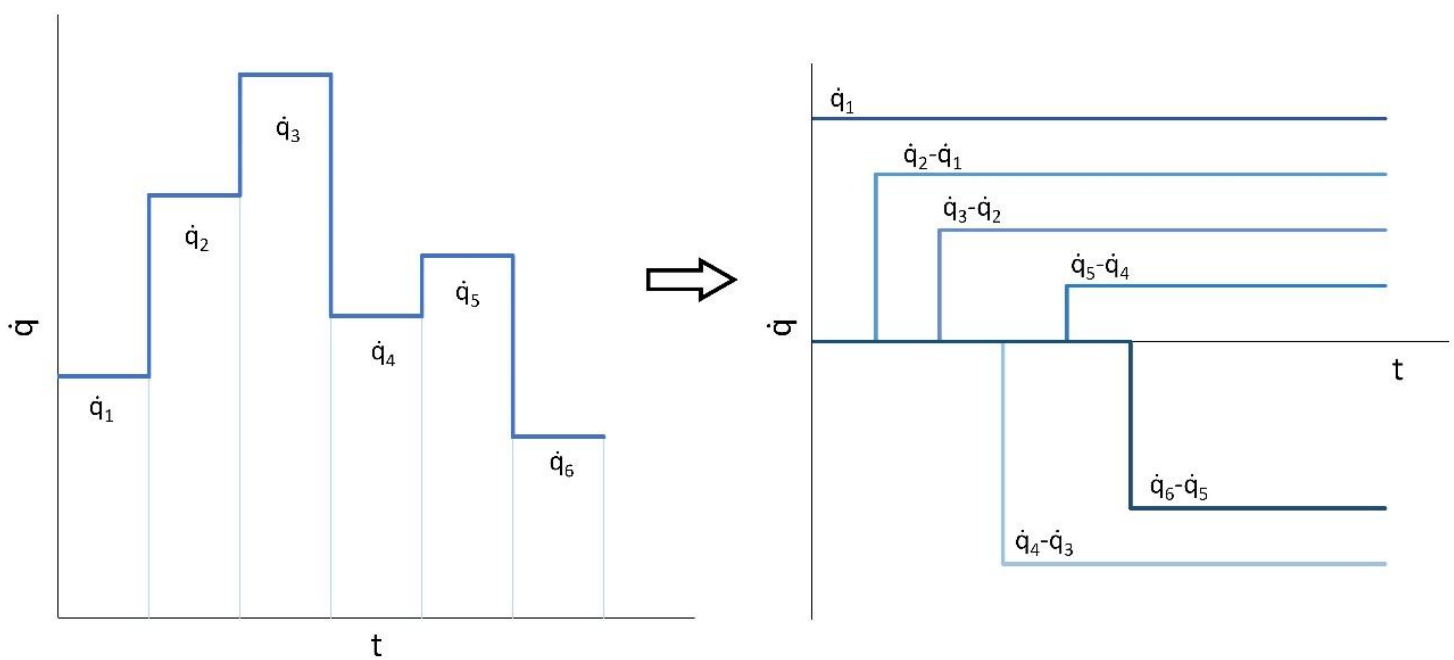

Figure 4: Superposition of steps for thermal load representation [29] 
The value of these load steps is obtained as the difference between one block and the previous one. So, the thermal load of one block can be calculated as a sum of all the previous load steps (Eq. 8).

$$
\dot{q}_{n}=\sum_{i=1}^{n}\left(\dot{q}_{i}-\dot{q}_{i-1}\right)
$$

Now, it is possible to obtain the borehole wall temperature by superposition of the response to the load steps until the corresponding time, as provided by the $\mathrm{g}$-function. Therefore, Eq. 7 becomes Eq. 9 .

$$
T_{b}(t)=T_{g}+\sum_{i=1}^{n} \frac{\dot{q}_{i}-\dot{q}_{i-1}}{2 \pi k} * g\left(\ln \left(\frac{t-t_{i}}{t_{s}}\right)\right)
$$

The computational cost of Eq. 9 increases with the simulation time, as the number of load steps increases too. In [7], a load aggregation technique is proposed in order to avoid this. Since the effect of the steploads stabilizes with time, after some certain time has passed, the older load blocks of the simulation can be combined in an average block, without losing the accuracy of the model. This way, it is possible to reduce the total number of load blocks and, thus, the total time required for the computation of Eq. 9.

Since this particular application of the g-function model might involve a great number of load blocks, instead of using bigger aggregation blocks, it is better to use variable size blocks, similar to the technique proposed in [33]. The solution proposed consists of a telescopic aggregation algorithm, based on two parameters: an aggregation factor, $k_{a}$, and a margin value, $m_{\mathrm{a}}$. Being $\Delta t$ the duration of the initial load blocks, the following steps describe the algorithm used in this work:

- Simulation time advances and load blocks (duration $\Delta t$ ) are added to the load profile. Those will be type 1 blocks from now on.

- Once there are a total of $k_{\mathrm{a}}+m_{\mathrm{a}}$ blocks of type 1, (corresponding to a time $\left.t=\left(k_{\mathrm{a}}+m_{\mathrm{a}}\right) \cdot \Delta t\right)$, first $k_{\mathrm{a}}$ blocks are aggregated in an average block of type 2, with a duration of $k_{\mathrm{a}} \Delta t$. So, the $k_{\mathrm{a}}+m_{\mathrm{a}}$ initial blocks are represented with one type 2 block and $m_{\mathrm{a}}$ type 1 blocks.

- After some time (equal to $k_{\mathrm{a}} \cdot \Delta t$ ), the next $k_{\mathrm{a}}$ blocks of type 1 will be also aggregated, leaving two blocks of type 2 and $m_{\mathrm{a}}$ blocks of type 1.

- This process keeps on until there are a total of $k_{a}+m_{a}$ blocks of type 2 and $m_{\mathrm{a}}$ blocks of type 2 . Then, the first $k_{\mathrm{a}}$ blocks of type two 
are aggregated in an average block of type 3 , with a duration of $k_{a}^{2} \cdot \Delta t$. This results in one type 3 block, ma type 2 blocks, and $m_{a}$ type 1 blocks.

Using this algorithm, it is possible to aggregate thermal loads using blocks that grow bigger as the total number of blocks increases with the simulation time. The margin factor $\left(m_{\mathrm{a}}\right)$ ensures that there will always be enough blocks of each type to keep the model accuracy. The algorithm can be extended to blocks as big as necessary, aggregating type 3 blocks into type 4 blocks and so on. Moreover, it is not necessary that all the blocks have the same duration, providing some extra flexibility to the model. Figure 5 shows a result example of this aggregation algorithm, with $k_{\mathrm{a}}=5$ and $m_{\mathrm{a}}=1$.

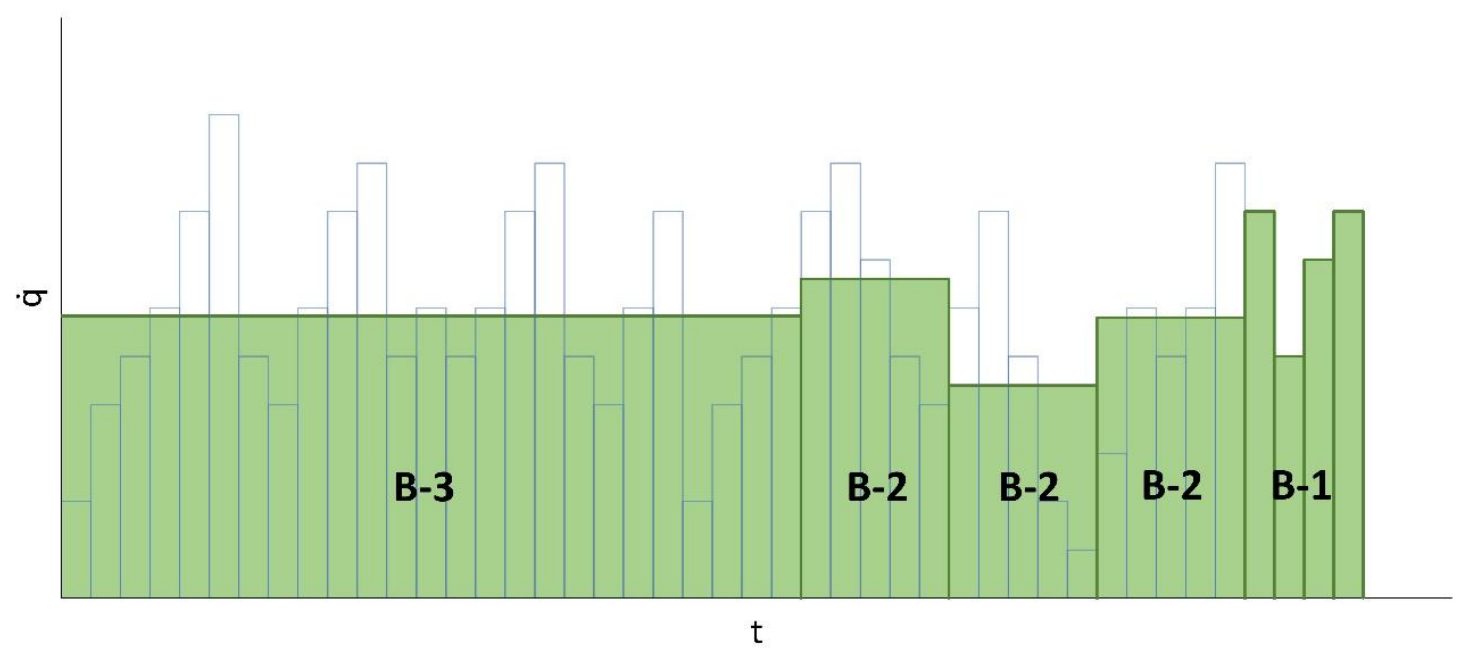

Figure 5: Load aggregation [29]

\section{Model validation}

\subsection{GeoCool Plant}

The ground source heat pump installation analyzed in this work and considered for the experimental validation of the developed GSHE model consists of a ground source heat pump installation for heating and cooling in a set of offices located at the Applied Thermodynamics Department of the Universitat Politècnica de València, in València, Spain. The installation was constructed in year 2004, in the framework of an FP5 European project named Geocool (Geothermal Heat Pump for Cooling and Heating along European coastal Areas) [34], and the research work on the geothermal plant continued in the framework of an FP7 European project called Ground-Med 
(Advanced ground source heat pump systems for heating and cooling in Mediterranean climate) [37], in years 2009 to 2014. The heat pump consists of a water-to-water reversible heat pump, single-stage on/off controlled working with propane, with a nominal heating capacity of $17 \mathrm{~kW}\left(35^{\circ} \mathrm{C}\right.$ return/17 ${ }^{\circ} \mathrm{C}$ return) and $14.7 \mathrm{~kW}\left(14{ }^{\circ} \mathrm{C}\right.$ return/25 ${ }^{\circ} \mathrm{C}$ return) of nominal cooling capacity. Figure 6 shows a schematic diagram of the installation.

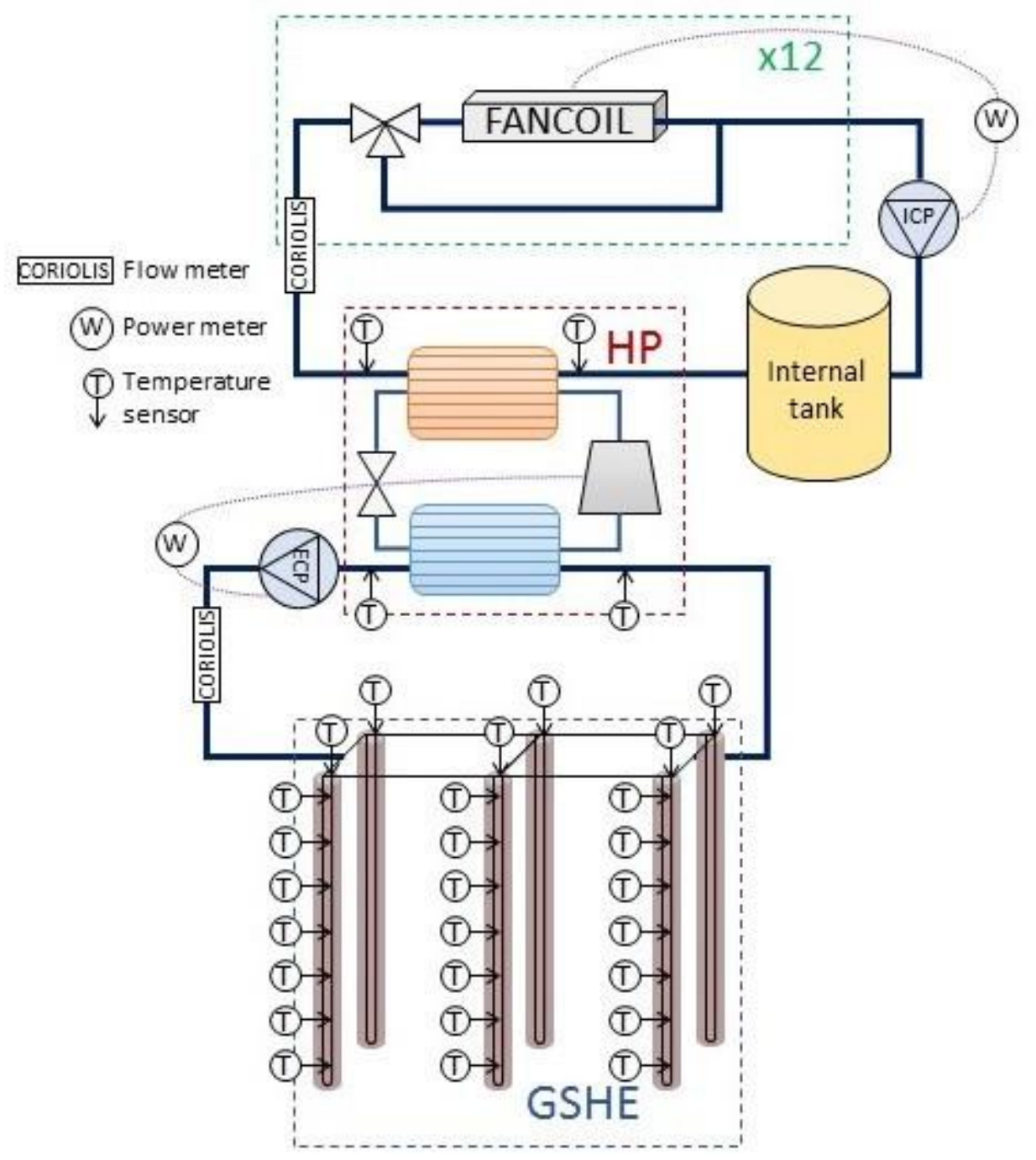

Figure 6: Schematic diagram of the ground source heat pump installation. Geocool Plant.

As it can be observed in Figure 6, there are two hydraulic loops in the installation. The internal loop which is coupled to the building (air conditioned area), and the external loop, coupled to the GSHE. 
The air conditioned area comprises approximately $250 \mathrm{~m}^{2}$, and it includes nine offices located in the east façade of the building, one computer room and a coffee room. Each office as well as the coffee room is equipped with one fan coil as a terminal unit, except for the computer room where there are two fan coils installed, making a total of twelve fan coil units connected in parallel. The corridor is not air conditioned. Each fan coil can be individually regulated by means of a thermostat and comfort temperature and fan speed can be selected by the user. A three-way valve, which is controlled by the thermostat of the room, regulates the control for each fan coil allowing the heating/cooling water to be modulated through the fan coil. All the system components except the GSHE and the fan coils are located in a machinery room in the basement of the department. The ambient temperature at the machinery room remains approximately constant at $22^{\circ} \mathrm{C}$ along the year. Regarding the outdoor ambient temperature, it corresponds to a typical Mediterranean mild weather, being the maximum ambient temperature equal to $35^{\circ} \mathrm{C}$ in summer and the minimum temperature during the winter equal to $7^{\circ} \mathrm{C}$ approximately.

The operation of the heat pump is governed by an electronic controller which, depending on the temperature of the return water from the internal circuit (fan coils), switches on or off the compressor of the heat pump. The default values for the water return temperatures at the internal circuit vary between $37^{\circ} \mathrm{C}$ and $43^{\circ} \mathrm{C}$ for heating mode and $12^{\circ} \mathrm{C}$ and $15^{\circ} \mathrm{C}$ for cooling mode. The internal circulation pump works continuously while the external circulation pump is governed by the controller of the heat pump, which activates the external circulation pump sixty seconds before activating the compressor and turns it off sixty seconds after the compressor. In order to vary the flow of water at the internal and external circuit, the facility has two inverters, one for each circulation pump. The overall system operation is controlled by a timer which is programmed to operate between $7 \mathrm{am}$ and $9 \mathrm{pm}, 5$ days per week, as the system is switched off during the weekends. Further information of the installation description can be found in [35] and [36].

The system has been completely monitored since 2005. The following variables are measured: temperature of the water at the inlet and outlet of the heat pump on both sides (evaporator and condenser); water mass flow rates at each hydraulic circuit; power consumption measured by two multifunctional power meters (one for the internal circuit which measures the power consumption of the fan coil units and the internal circulation pump, and another one for the external circuit which measures the compressor and the external circulation pump 
power consumption). The location of temperature sensors and flow meters on the hydraulic circuits, as well as the power meters, can be observed in Figure 6. In addition, the temperature and relative humidity in the offices is measured as well. The data from this sensor network is collected by a data acquisition unit Agilent HP34970A with plug-in modules HP34901A. Table 2 shows the measurement uncertainties of the different sensors installed in the facility.

\begin{tabular}{|l|l|l|}
\hline $\begin{array}{l}\text { Experimental } \\
\text { measurement }\end{array}$ & Type of sensor used & Accuracy \\
\hline Temperature & Four wire PT100 & $\pm 0.1 \mathrm{~K}$ \\
\hline Water flow rate & $\begin{array}{l}\text { Coriolis flow meter, Danfoss, model massflo } \\
\text { MASS 6000 }\end{array}$ & $<0.1 \%$. \\
\hline Power consumption & $\begin{array}{l}\text { Multifunctional power meters by Gossen } \\
\text { Metrawatt, model A2000 }\end{array}$ & $\begin{array}{l} \pm 0.5 \% \text { of the } \\
\text { nominal value }\end{array}$ \\
\hline
\end{tabular}

Table 2: Type of sensors installed at Geocool plant and their uncertainties.

\subsubsection{Ground Source Heat Exchanger}

The GSHE consists of six boreholes of $50 \mathrm{~m}$ deep connected in a balanced parallel configuration. Each borehole contains a single polyethylene U-tube of $25.4 \mathrm{~mm}$ internal diameter, with a $7 \mathrm{~cm}$ separation between the upward and downward tubes. The overall diameter of the borehole is $15 \mathrm{~cm}$. The six boreholes are arranged in a $2 \times 3$ rectangular grid (18 m2), with a $3 \mathrm{~m}$ separation between them. All boreholes are filled with sand and finished with a bentonite layer at the top to avoid intrusion of pollutants in the aquifers. The values of the thermal properties of the ground (conductivity of $1.43 \mathrm{~W} / \mathrm{mK}$ and volumetric heat capacity of $2.25 \mathrm{MJ} / \mathrm{m}^{3} \mathrm{~K}$ ) were obtained by means of a laboratory analysis performed on soil samples, although a high uncertainty (around 20\%) in the estimation of the ground thermal conductivity was observed [35]. It should be pointed out that both values were measured in samples of dry soil. However, the phreatic level is 3.5 $\mathrm{m}$. So, in practice, it is expected that the surrounding soil is saturated, which would turn into higher values of the conductivity and volumetric heat capacity, as it was pointed out in [29] and [38]. Measurements of the ground undisturbed temperature were undertaken at the Geocool plant and the registered values (around $19.5^{\circ} \mathrm{C}$ ) were very close to the water temperature coming from the ground loop, which is around $20^{\circ} \mathrm{C}$ as presented in [35] and [36]. Finally, as it can be observed in Figure 6, water temperature is measured at the inlet and outlet of each one of the six boreholes connected in parallel. Furthermore, in three of the boreholes, grout temperatures every $10 \mathrm{~m}$ of depth are also measured. Further details about the GSHE can be found in [29] and in [36]. 


\subsection{G-function generation}

In this paper, the g-function is generated from a FEM (Finite Element Method) model described in [39]. Numerical modeling of multiple borehole fields usually is handicapped with large computing times in comparison with analytical solutions; however, a detailed description of the thermal process is achieved with numerical solutions. For the sake of simplicity in the long term analysis and reduction of the computing time, the model presented in [39], which will be referred as the HCM-model, considers the boreholes as cylinder sources which are filled with a highly conductive material (HCM). Moreover, the HCM model takes advantage of the thermal conductivity of the highly conductive material to impose a uniform temperature boundary condition at the borehole wall.

The procedure to impose a uniform temperature boundary condition at the borehole walls with the concept of the HCM material is explained briefly below and further details can be found in [39]. In the HCM model, a uniform temperature condition is imposed by physically connecting the boreholes, which are filled with the fictitious HCM, with a bar, made of $\mathrm{HCM}$ and placed some centimeters above the ground surface by using auxiliary HC cones. Then, a total constant heat flow is imposed at the top of the bar and the heat is naturally distributed to each borehole. The value of the thermal conductivity of the $\mathrm{HCM}\left(\mathrm{K}_{\mathrm{HCM}}=10^{10}\right)$ allows a uniform temperature boundary condition to be accomplished at the borehole wall.

A detailed description of the HCM-model with special attention to the UPV installation is presented in [38]. Since the UPV borehole field is characterized by a rectangular pattern with a symmetrical distribution of the boreholes, an adiabatic condition is present at the wall between the mirror halves, allowing a reduction of the computing domain by half. In Figure 7, half of the UPV bore field configuration and its surrounding ground is drawn according to its geometrical characteristic, as described in Table 3.

\begin{tabular}{|c|c|}
\hline Geometrical aspect & Value \\
\hline$I / H$ & 0.074 \\
\hline$r_{b} / H$ & 0.0016 \\
\hline$B / H$ & 0.063 \\
\hline
\end{tabular}

Table 3: Geometrical aspect ratios - UPV site 


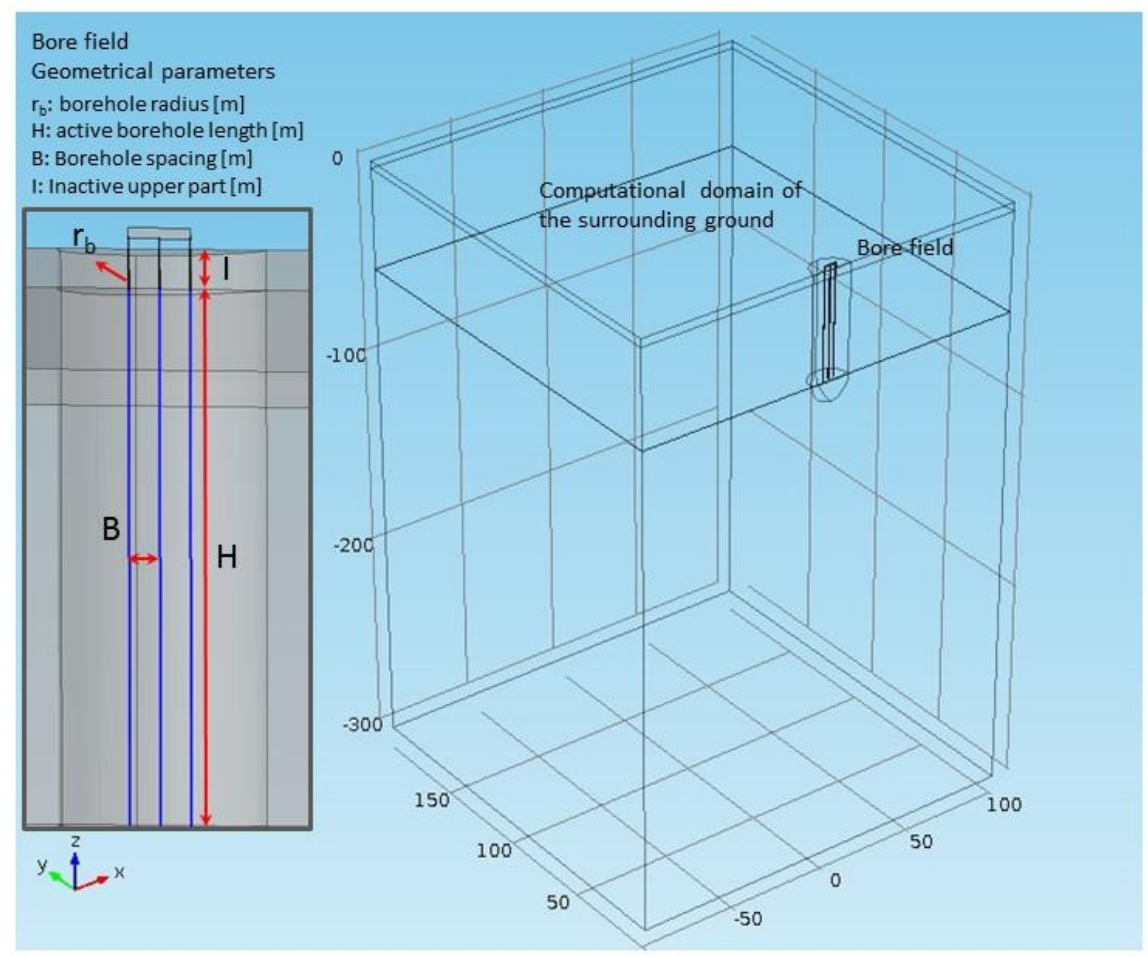

Figure 7: Computational domain of the UPV bore field configuration

The computational domain, surrounding ground and borehole field, presents a total volume of about $200 \times 200 \mathrm{~m}$ in the horizontal plane with 300 $\mathrm{m}$ depth, while the borehole field volume is only $1.57 \times 6.15 \mathrm{~m}$ with $51 \mathrm{~m}$ depth (for the execution of the boreholes, a ditch of $1 \mathrm{~m}$ depth was drilled apart from the $50 \mathrm{~m}$ depth of the boreholes). The HCM elements, cylinders to fill the boreholes, bar, and auxiliary cones; are then inserted, as explained in [39].

Then, the thermal properties of the ground and of the $\mathrm{HCM}$ are defined and referenced to the surrounding ground and to the boreholes, the HCM bar and the auxiliary cones, respectively. A zero temperature condition is fixed at the ground domain boundaries, except at the borehole walls. A uniform temperature boundary condition is imposed at the borehole walls, as explained previously. In the last steps the parameters in the solver for a time dependent study are defined and the construction of the mesh is carried out, as explained in [38]. It should be noted that the g-function generation does not require either the thermal properties of the ground or its undisturbed temperature at the site of the installation. Typical values for these properties are adequate for the calculation of the g-function. Figure 
8 shows the $g$-function for the UPV bore field geometry.

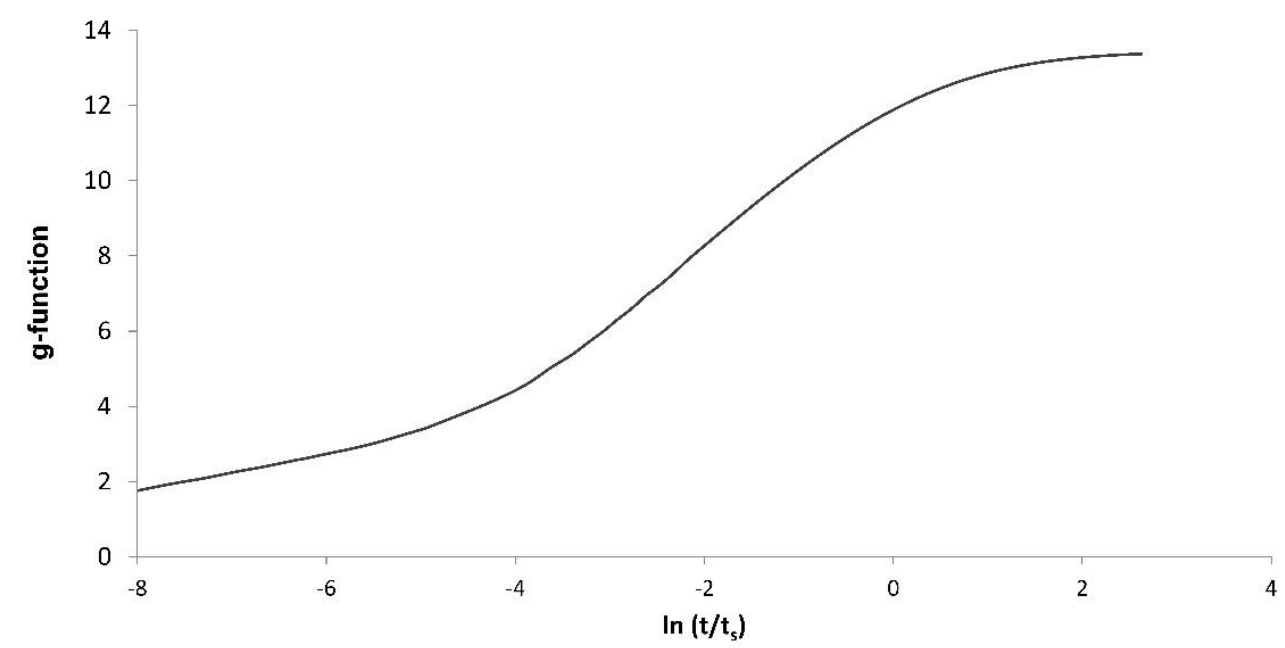

Figure 8: G-function according to the geometrical aspect ratios of the UPV bore field

\subsection{TRNSYS simulation}

Both B2G and g-function models have been implemented using new TRNSYS types specially developed for this application. In the B2G model, the parameters considered for the TRNSYS type correspond to the ones required by the model. The values of the parameters used in this work are presented on table 4 (with thermal capacitances and resistances expressed as node values).

The B2G model is coupled to the g-function using a reset temperature. During the simulation, a control variable establishes the moment when the B2G initial temperature should be reset to the value calculated with the g-function. At this point, the temperatures of the ground and grout nodes of the B2G model are fixed to this reset temperature. Therefore, the reset time should coincide with the time when a load block is formed at the gfunction type (so that the temperature calculated by this model takes into account all the thermal load until this point). There are different options for representing the thermal load, depending on the distribution and duration of the load blocks. Figure 9 shows the three options considered in this work. Option 1 consists in representing the thermal load as a daily block of 24 hours, so the B2G model resets its temperature every day at 00:00 h. Option 2 also takes into account 24 hour blocks, but they represent the thermal load from the moment when the installation starts working one day 
until the starting of the next day. With this option, temperatures at B2G will be reset at the same moment when the system starts its operation each day. Finally, option 3 divides the thermal load of each day into two load blocks, according to the typical operation of the system, thus producing a block of 15 hours of heat injection/extraction and a block of 9 hours with no thermal load at all. Again, with this option, the reset time for the B2G model will correspond to that of the start of the system operation for each day.

\begin{tabular}{|c|c|c|}
\hline \multicolumn{3}{|c|}{ Thermophysical properties } \\
\hline Ground thermal conductivity & $k_{\mathrm{g}}$ & $2.09 W m^{-1} K^{-1}$ \\
\hline Grout thermal conductivity & $k_{b}$ & $2.09 \mathrm{~W} \mathrm{~m}^{-1} \mathrm{~K}^{-1}$ \\
\hline Ground volumetric thermal capacitance & $C_{g}$ & $3200 \mathrm{~kJ} \mathrm{~m}^{-3} \mathrm{~K}^{-1}$ \\
\hline Grout volumetric thermal capacitance & $c_{b}$ & $3200 \mathrm{~kJ} \mathrm{~m}^{-3} \mathrm{~K}^{-1}$ \\
\hline Ground thermal diffusivity & $\alpha_{g}$ & $0.002351 m^{2} h^{-1}$ \\
\hline \multicolumn{3}{|c|}{ Geometrical characteristics } \\
\hline Borehole diameter & $D_{\mathrm{b}}$ & 150 \\
\hline External U-pipe diameter & $D_{\mathrm{p}, \mathrm{e}}$ & $32 \mathrm{~mm}$ \\
\hline Internal U-pipe diameter & $D_{\mathrm{p}, \mathrm{i}}$ & $25.4 \mathrm{~mm}$ \\
\hline Shank spacing (center-to-center) & W & $\mathrm{mm}$ \\
\hline Depth & $\mathrm{L}$ & $50 \mathrm{~m}$ \\
\hline \multicolumn{3}{|c|}{ Model parameters } \\
\hline Number of nodes & $\mathrm{n}$ & $150-$ \\
\hline Borehole node thermal capacitance & $C_{\mathrm{b} 1}-C_{\mathrm{b} 2}$ & $17.56 J K^{-1}$ \\
\hline Ground node thermal capacitance & $\mathrm{C}_{\mathrm{g}}$ & $1200 J K^{-1}$ \\
\hline Borehole conductive thermal resistance & $R_{\mathrm{b} 1}-R_{\mathrm{b} 2}$ & $0.2738 K W^{-1}$ \\
\hline Pipe to pipe thermal resistance & $R_{\mathrm{pp}}$ & $0.8525 K^{-1}$ \\
\hline Borehole to borehole thermal resistance & $R_{\mathrm{bb}}$ & $0.4257 K^{-1}$ \\
\hline Borehole to ground thermal resistance & $R_{\mathrm{g}}$ & $0.2772 K^{-1}$ \\
\hline Equivalent pipes diameter & $D_{\text {eq }}$ & $45 \mathrm{~mm}$ \\
\hline Borehole node position & $D_{\mathrm{x}}$ & $150 \mathrm{~mm}$ \\
\hline Ground radial penetration diameter & $D_{\mathrm{gp}}$ & $860 \mathrm{~mm}$ \\
\hline Ground nodes position & $D_{1}$ & $505 \mathrm{~mm}$ \\
\hline
\end{tabular}

Table 4: Main parameters adopted in the present work. 


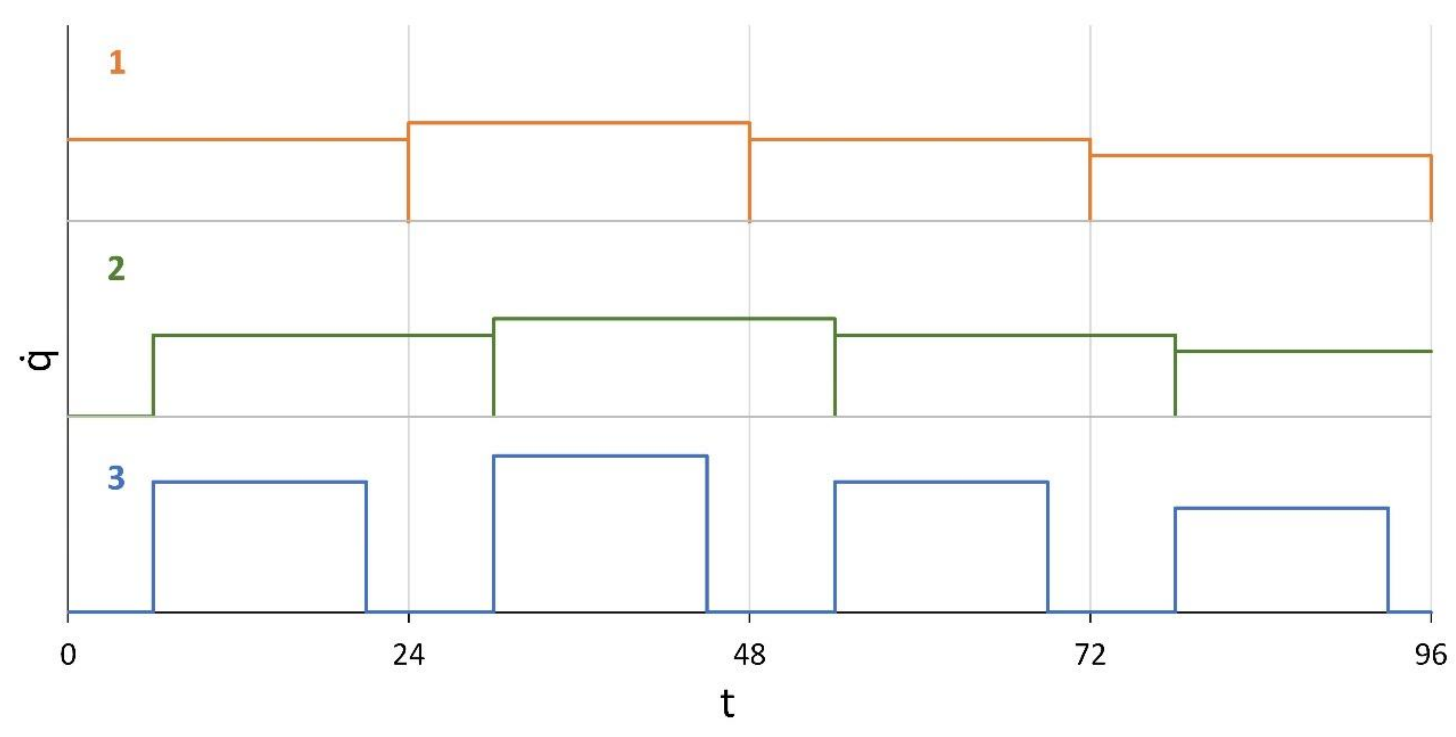

Figure 9: Three options for the thermal load blocks configuration

An initial test was performed in order to check which option of thermal load representation produces the most accurate results. Figure 10 shows the resulting temperature evolution for a simulation of one week, compared to the experimental one, for the three load blocks options. As it can be observed in Figure 10, option 3 produces the best results, since it is a better representation of the way the experimental thermal load is distributed.

In order to determine the aggregation and margin factors of the $\mathrm{g}$ function load aggregation algorithm, an analysis of the effect of this parameters on the temperature prediction is performed. Figure 11 shows a comparison of the calculated temperature, with $k_{a}=\{5,10\}$ y $m_{a}=5$ and without aggregation, for a simulation period of one year and 24 hours load blocks. All the results shown in Figure 11 are really similar, therefore proving that the application of the aggregation algorithm has a negligible effect on the borehole wall temperature prediction.

Table 5 compares the results obtained with several possible combinations of values for the parameters $k_{\mathrm{a}}$ and $m_{\mathrm{a}}$. For the comparison, the maximum absolute error has been obtained in a simulation with the characteristics as the one shown in Figure 11. On the other hand, the maximum number of load blocks that are required for the simulation is also calculated and shown in table 5 . The maximum number of blocks is directly related with the memory size required to store all the data and the computational cost of Eq. 9. 

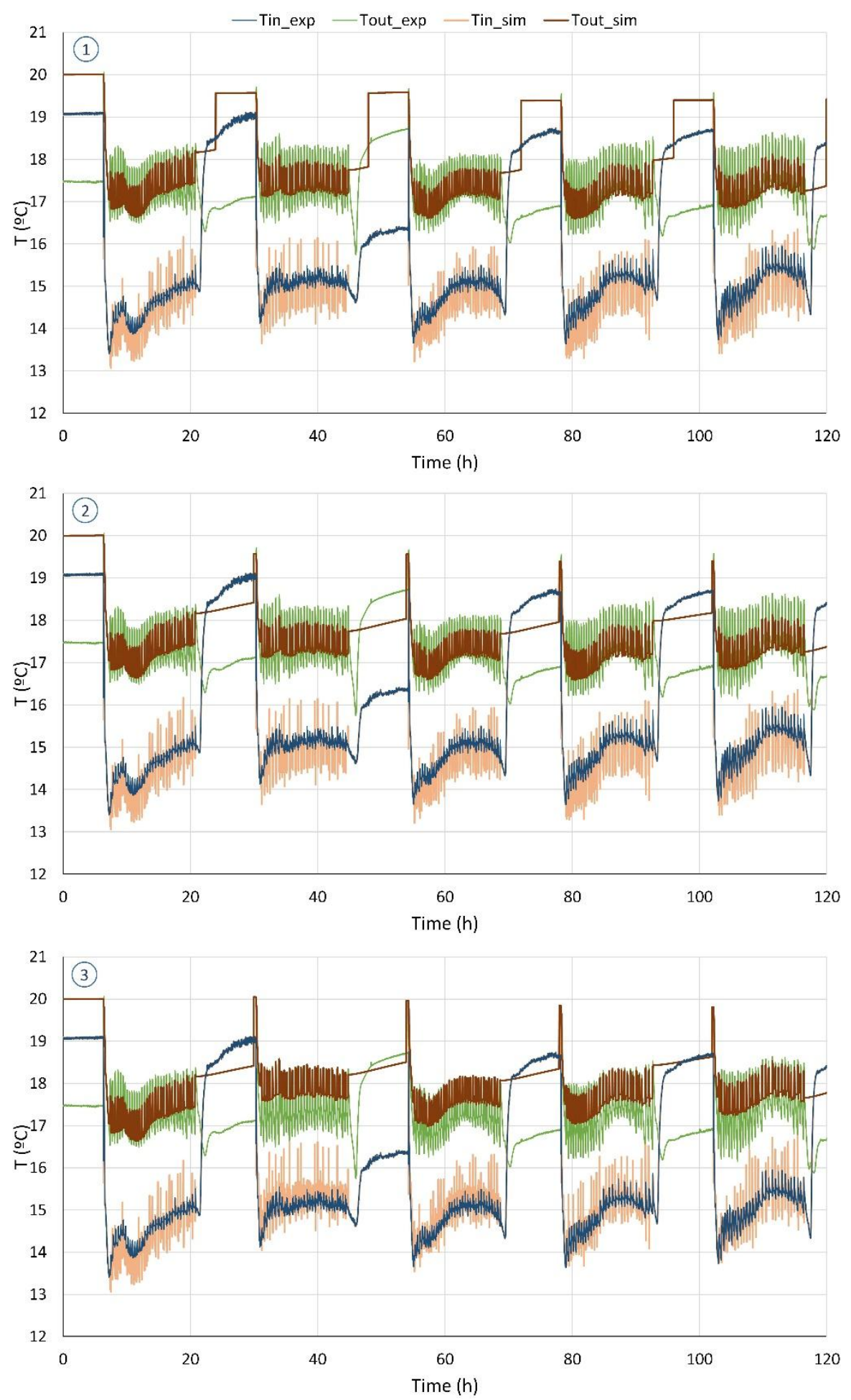

Figure 10: One Week results for the different options for the thermal load blocks 


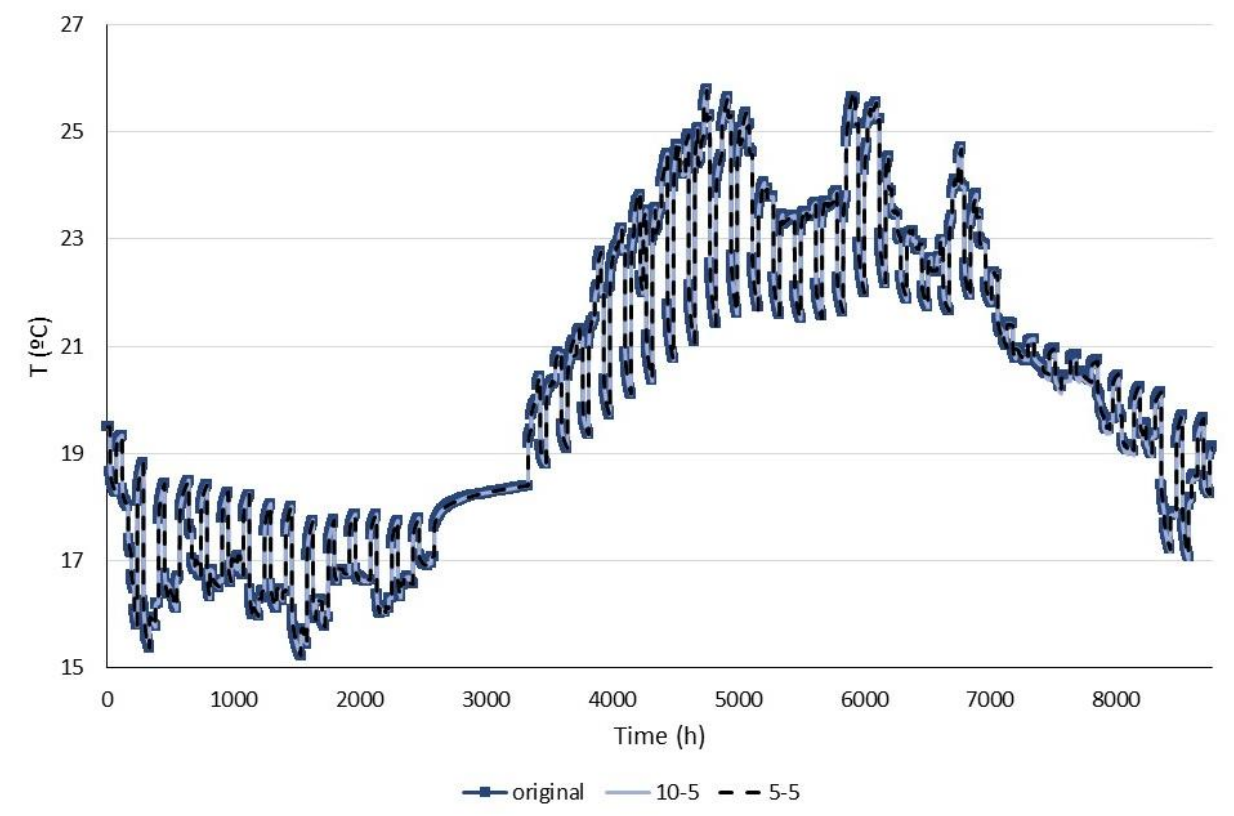

Figure 11: Comparison of results with and without load aggregation $\left(k_{\mathrm{a}}-m_{\mathrm{a}}\right)$ [29]

\begin{tabular}{|c|c|c|c|c|}
\hline \multicolumn{5}{|c|}{ Maximum absolute Error (K) } \\
\hline$k_{a} m_{a}$ & 1 & 5 & 10 & 20 \\
\hline 5 & 0.45 & 0.08 & 0.04 & 0.03 \\
\hline 10 & 0.54 & 0.13 & 0.13 & 0.02 \\
\hline 20 & 0.59 & 0.13 & 0.06 & 0.03 \\
\hline 50 & 0.76 & 0.24 & 0.14 & 0.06 \\
\hline 100 & 1.06 & 0.58 & 0.45 & 0.31 \\
\hline \multicolumn{5}{|c|}{ Number of Blocks } \\
\hline & 1 & 5 & 10 & 20 \\
\hline & & & & \\
\hline 5 & 16 & 27 & 39 & 65 \\
\hline 10 & 22 & 30 & 47 & 76 \\
\hline 20 & 37 & 41 & 45 & 77 \\
\hline 50 & 56 & 60 & 65 & 74 \\
\hline 100 & 102 & 106 & 11 & 121 \\
\hline
\end{tabular}

Table 5: Maximum absolute error $(\mathrm{K})$ and maximum number of blocks needed for a simulation of one year depending on the values of the parameters $k_{\mathrm{a}}$ and $m_{\mathrm{a}}$ 
As it could be expected, the accuracy of the model decreases when $k_{a}$ is increased, while increasing the margin $m_{a}$ produces a lower absolute error. However, for the total number of blocks, the behaviour is just the opposite: as the parameter $k_{a}$ increases, fewer blocks will be necessary; but, increasing $m_{\mathrm{a}}$ results in a higher number of blocks required. The values finally considered are $k_{\mathrm{a}}=10$ and $m_{\mathrm{a}}=5$, which have been selected taking into account the possibility of greater simulation times or using shorter blocks (which would increase considerably the total number of blocks required for the simulation). The solution adopted guarantees a high enough accuracy of the g-function model $(<0.13 \mathrm{~K})$, while keeping a low computational cost.

\section{Results and discussion}

The B2G model has been previously validated in [30] and [31]. In both works, the validation was performed on a short-term basis, only with the B2G model predicting the evolution of the fluid temperature for a period of 10-15 hours. In [30], experimental data corresponding to two step-tests carried out at a BHE located at Stockholm, Sweden, were used for the validation. Besides, in [31], the validation was extended using experimental data from the GSHP system located at UPV corresponding to a step-test performed on the installation but also with data corresponding to a typical operation day of the system. B2G model has proved to be able to correctly reproduce the characteristic dynamic behaviour of the BHE.

Therefore, the present work is focused on the validation of the global $\mathrm{BHE}$ model, formed by the combination of the B2G and $\mathrm{g}$-function models, for the prediction of the temperature evolution along the days. The experimental data taken into account for the validation correspond to one month of typical performance of the GSHP system located at UPV. The experimental thermal load injected to the ground in one of the six boreholes will be used as an input for the simulation, together with the water mass flow rate. With these variables, it is possible to calculate the temperature of the water entering the $\mathrm{BHE}$, simulating the effect of the heat pump, thus resulting in a closed-loop simulation. Simultaneously, the thermal load will be used by the g-function in order to calculate the initial temperature of the ground and the grout for each day.

The evolution of the temperatures along one week of simulation has been presented in Figure 10. Figure 12 presents only the results corresponding to the option selected for the thermal load representation, that is, using blocks of 15 hours of thermal load and 9 hours of no load. 


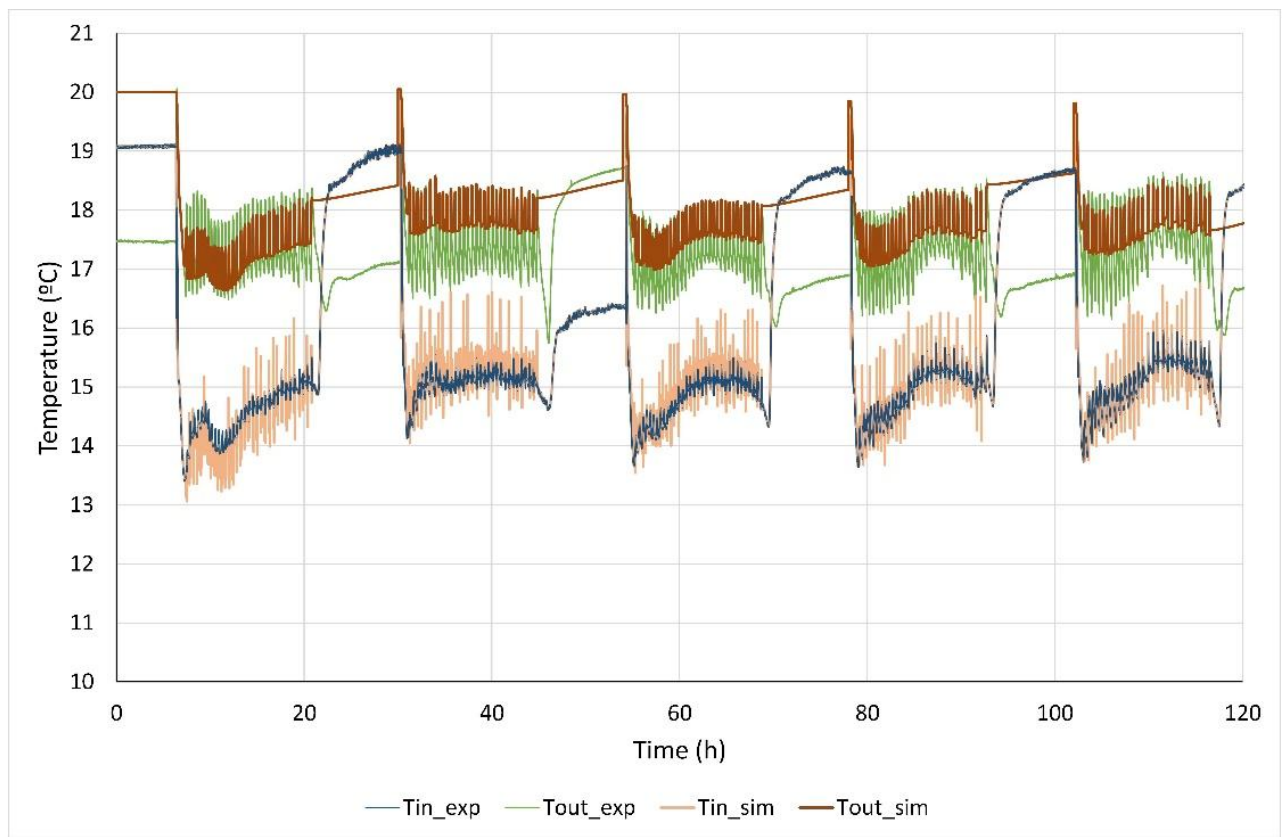

Figure 12: One week simulation results

Extending the simulation time to a whole month it is possible to obtain the temperature evolution shown in Figure 13. In Figure 13, it is observed that the temperature evolution obtained with the complete BHE model correctly represents the experimental measurements. The gfunction seems to present a slightly lower thermal inertia than the real GSHE shows, providing a slightly higher variation on the temperatures. However, the evolution of the temperatures along the days during the whole month reflects the same behaviour as the experimental ones, with enough accuracy for the purposes of the model.

Nevertheless, in order to be able to fairly compare the simulation results with the experimental measurements, averaged values should be used. Figure 14 shows the daily temperature averages for all the simulated days. As it can be seen in Figure 14, the evolution of the daily values of the simulated temperatures perfectly reflects that of the experimental ones. The maximum deviation obtained is of $0.2 \mathrm{~K}$.

Finally, the monthly average is calculated from the daily values of each month. The results of this calculations are shown in Eq. 10. The difference between the simulated and experimental values of these parameters is less than $0.1 \mathrm{~K}$. Therefore, the developed GSHE model has proven to be precise enough for simulation purposes. 

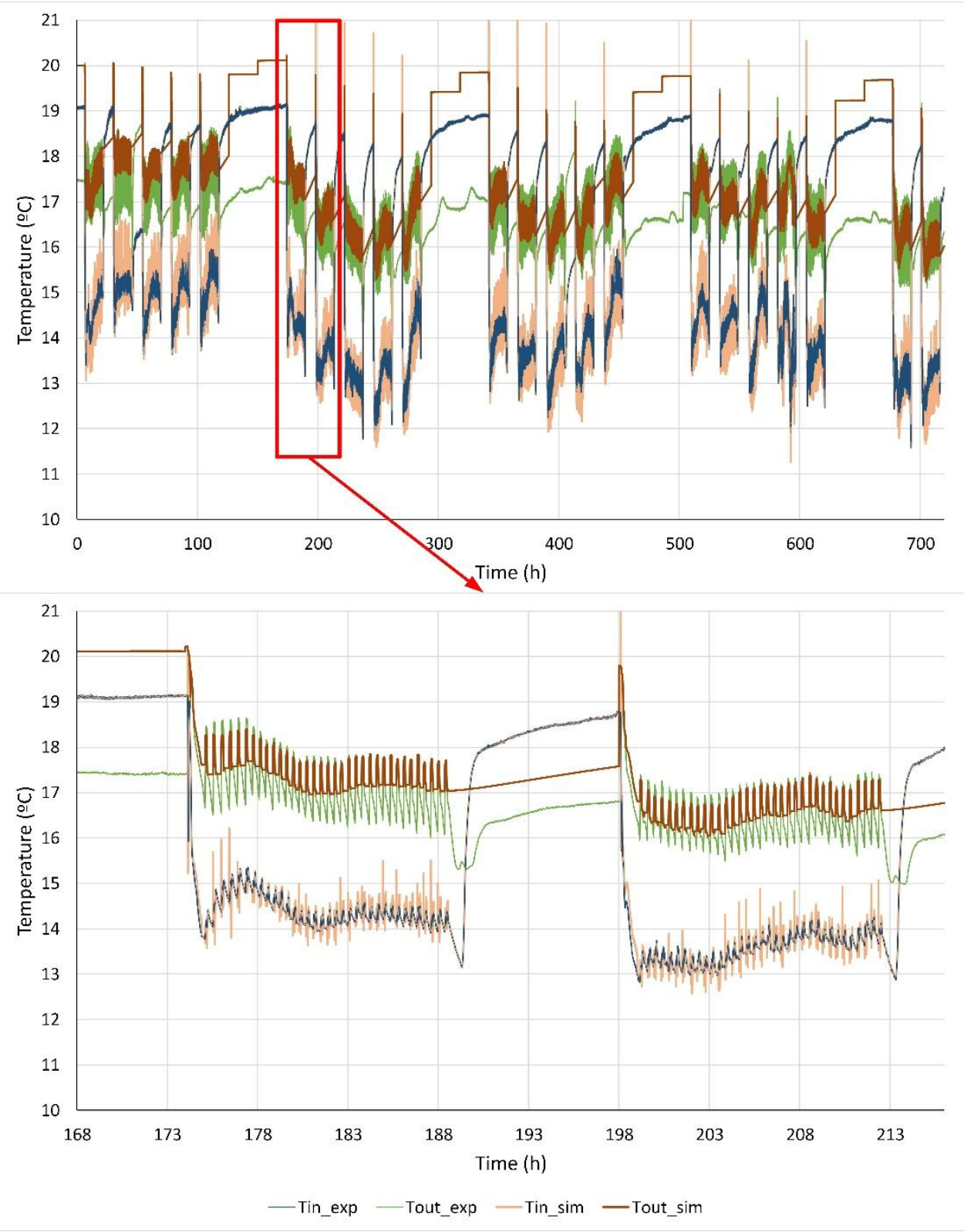

Figure 13: One month simulation results 


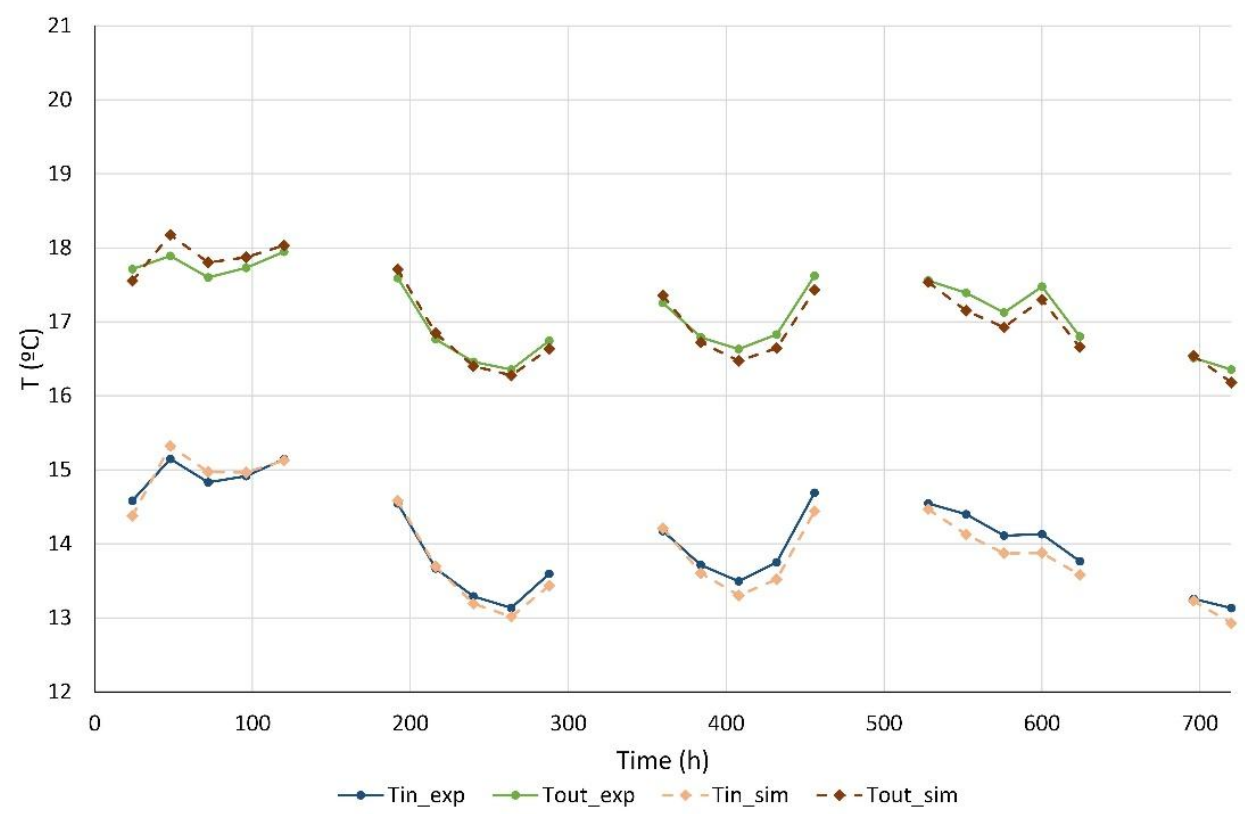

Figure 14: Daily average temperature values for a one month simulation

$$
\begin{gathered}
\mathrm{T}_{\text {in,exp }}=14.09^{\circ} \mathrm{C} \\
\mathrm{T}_{\text {in,slm }}=13.99^{\circ} \mathrm{C} \\
\mathrm{T}_{\text {out, exp }}=17.14^{\circ} \mathrm{C} \\
\mathrm{T}_{\text {out, slm }}=17.1^{\circ} \mathrm{C}
\end{gathered}
$$

\section{Conclusions}

In this paper, a complete model of a ground source heat exchanger has been presented. The model is based on decoupling the short-term and long- term responses of the GSHE, allowing the use of faster model in both time scales.

For the short-term, the B2G model is used. The B2G model has been already validated by its own, providing a very accurate prediction of the dynamic behavior of the BHE. On the other hand, for the longterm prediction, the g-function model is used.

Implementing the g-function model requires taking into account certain considerations. Regarding this, a telescopic aggregation algorithm is presented, based on creating load blocks of progressive incrementing size. This algorithm allows reducing the total computational cost of the g-function model, while keeping a good accuracy on the temperature prediction. Besides, a study of different 
configurations of the thermal load blocks has been carried out. The configuration adopted consists in using blocks of 15 hours with the average thermal load corresponding to a day, followed by blocks of 9 hours of zero load, which best represents the real thermal load injected/extracted in the GSHE.

The combination of the two models is done by using the g-function to calculate the initial ground temperature for each working day of the GSHP. From this initial temperature, the B2G model simulates the temperature evolution along the day.

The complete GSHE developed has proved to be able to accurately reproduce the evolution of the temperature of the water exiting the BHE. On one hand, the B2G model ensures a good reproduction of the dynamic behavior of the BHE during the system daily operation. On the other hand, the g-function model allows a correct prediction of the longterm temperature evolution, both on a daily and a monthly basis. Therefore, the developed model is perfectly suitable for simulation purposes and for including it on a whole system model.

\section{Acknowledgements}

This workwas supported by the FP7 European project "Advanced ground source heat pump systems for heating and cooling in Mediterranean climate" (Ground-Med, contract number TREN/FP7EN/218895). 


\begin{tabular}{|c|c|c|}
\hline \multicolumn{3}{|c|}{ Nomenclature } \\
\hline$\alpha$ & Thermal diffusivity $\left[\mathrm{m}^{2} / \mathrm{s}\right]$ & Subscripts \\
\hline B & Borehole spacing [m] & 1 Downward pipe zone \\
\hline $\mathrm{BHE}$ & Borehole heat exchanger & 2 Upward pipe zone \\
\hline C & Volumetric thermal capacity $\left[\mathrm{J} / \mathrm{m}^{3} \mathrm{~K}\right]$ & b borehole \\
\hline C & Thermal capacitance $[\mathrm{J} / \mathrm{K}]$ & bb borehole node to borehole node \\
\hline D & diameter $[\mathrm{m}]$ & bw borehole wall \\
\hline$g$ & g-function [-] & eq equivalent \\
\hline GSHE & Ground source heat exchanger & $f \quad$ fluid \\
\hline GSHP & Ground source heat pump & $g \quad$ ground \\
\hline $\mathrm{H}$ & Active borehole length [m] & ground penetration \\
\hline I & Inactive upper part of the borehole [m] & in Inlet \\
\hline $\mathrm{k}$ & conductivity $[\mathrm{W} / \mathrm{mK}]$ & p pipe \\
\hline$k_{\mathrm{a}}$ & aggregation factor $[-]$ & pp pipe node to pipe node \\
\hline $\mathrm{L}$ & Total borehole length $[\mathrm{m}]$ & out Outlet \\
\hline$\dot{m}$ & Mass flow rate $[\mathrm{kg} / \mathrm{h}]$ & $\mathrm{x}$ borehole node position \\
\hline$m_{\mathrm{a}}$ & aggregation margin [-] & \\
\hline $\mathrm{n}$ & number of nodes [-] & \\
\hline$\dot{q}$ & Thermal load [W/m] & \\
\hline$r$ & radius $[\mathrm{m}]$ & \\
\hline $\mathrm{R}$ & Thermal resistance [K/W] & \\
\hline $\mathrm{R}_{\mathrm{BHE}}$ & Borehole thermal resistance $[\mathrm{mK} / \mathrm{W}]$ & \\
\hline $\mathrm{R}_{12}$ & Fluid to fluid thermal resistance [mK/W] & \\
\hline $\mathrm{t}$ & Time $[s]$ & \\
\hline$t_{\mathrm{s}}$ & Characteristic time [s] & \\
\hline $\mathrm{T}$ & Temperature $\left[{ }^{\circ} \mathrm{C}\right]$ & \\
\hline$v$ & velocity $[\mathrm{m} / \mathrm{s}]$ & \\
\hline W & shank spacing [m] & \\
\hline z & Borehole depth coordinate [m] & \\
\hline
\end{tabular}




\section{References}

[1] Environmental Protection Agency: http://www.epa.gov/region1/eco/energy/re_geothermal.html, 14/03/2013.

[2] Urchueguía, J.F., Zacarés, M., Corberán, J.M., Montero, A., Martos, J., Witte, $\mathrm{H}$., 2008. Comparison between the energy performance of a ground coupled water to water heat pump system and an air to water heat pump system for heating and cooling in typical conditions of the European Mediterranean coast. Energy Conversion and Management; 49, 2917-2923.

[3] Fidorow, N., Szulgowska-Zgrzywa, M., 2015. The influence of the ground coupled heat pump's labor on the ground temperature in the boreholes e Study based on experimental data. Applied Thermal Engineering; 82, 237-245.

[4] Pu, L., Li, k., Tan, H., Li, Y. 2015. Simulation study on the thermal performance of vertical U-tube heat exchangers for ground source heat pump system. Applied Thermal Engineering; 79,202-213.

[5] Yang, H., Cui, P., Fang, Z.,2010. Vertical-borehole ground-coupled heat pumps: A review of models and systems. Appl Energ;87,16-27.

[6] Eskilson P., 1987. Thermal analysis of heat extraction boreholes. PhD Thesis, University of Lund, Sweden.

[7] Yavuzturk, C., Spitler, JD.,1999. A Short Time Step Response Factor Model for Vertical Ground Loop Heat Exchangers. ASHRAE Trans;105(2),475-85.

[8] Spitler, JD., 2000. GLHEPRO - A Design Tool For Commercial Building Ground Loop Heat Exchangers. Proceedings of the Fourth International Heat Pumps in Cold Climates Conference, Aylmer, Québec. August 17-18.

[9] Hellström, G., Sanner, B.,1994. Earth energy designer: software for dimensioning of deep boreholes for heat extraction. Sweden: Department of Mathematical Physics, Lund University.

[10] Cimmino, M., Bernier, M., Adams, F., 2013. A contribution towards the determination of $\mathrm{g}$-functions using the finite line source. Applied Thermal Engineering; 51,401-412.

[11] Priarone, A., Fossa, M., 2015. Modelling the ground volume for numerically gener- ating single borehole heat exchanger response factors according to the cylindrical source approach. Geothermics; 58,32-38.

[12] Beier, R.A., 2014. Transient heat transfer in a U-tube borehole heat exchanger. Applied Thermal Engineering; 62, 256-266.

[13] Eskilson, P., Claesson, J., 1988. Simulation model for thermally interacting heat extraction boreholes. Num Heat Transf; 13,149-65.

[14] Bauer, D., Heidemann, W., Müller-Steinhagen, H., Diersch, HJG.,2011. Thermal resistance and capacity models for borehole heat exchangers.Int $\mathrm{J}$ Energ Res; 35,312-20.

[15] Bauer,D., Heidemann, W., Diersch, HJG., 2011. Transient 3D analysis of borehole heat ex- changer modeling. Geothermics; 40, 250-60.

[16] Pasquier, P., Marcotte, D., 2012. Short-term simulation of ground heat exchanger with an improved TRCM. Renew Energ ;46, 92-9.

[17] Lamarche, L., Kajl, S., Beauchamp, B., 2010. A review of methods to evaluate borehole ther- mal resistances in geothermal heat-pump systems. Geothermics, 39,187-200.

[18] Diersch, HJG., Bauer, D., Heidemann, W., Rühaak, W., Schätzl, P., 2011, Finite element modeling of borehole heat exchanger systems Part 1: Fundamentals. Computers \& Geo- sciences;37,1122-35.

[19] Diersch, HJG., Bauer, D., Heidemann, W., Rühaak, W., Schätzl, P., 2011. Finite 
element mod- eling of borehole heat exchanger systems Part 2. Numerical simulation. Computers \& Geosciences;37,1136-47.

[20] Esen, H., Inalli M, Esen, Y, 2009. Temperature distributions in boreholes of a vertical ground-coupled heat pump system. Renew Energ;34,2672-9.

[21] Lee, CK., Lam, HN.,2008. Computer simulation of borehole ground heat exchangers for geothermal heat pump systems. Renew Energ;33,1286-96.

[22] Kim, E., Roux, J.J. Rusaouen, G., Kuznik, F., 2010. Numerical modelling of geother- mal vertical heat exchangers for the short time analysis using the state model size reduction technique. Applied Thermal Engineering; 30,706-714.

[23] Wang, J., Long, E., Qin, W. 2013. Numerical simulation of ground heat exchangers based on dynamic thermal boundary conditions in solid zone. Applied Thermal Engineering;59, 106-115.

[24] Zarrella, A., Scarpa, M., De Carli, M., 2011. Short time-step performances of coaxial and double U-tube borehole heat exchangers: Modeling and measurements. HVAC\&R Research;17(6), 959-76.

[25] Yang W, Shi M, Liu G, Chen Z., 2009. A two-region simulation model of vertical $U$-tube ground heat exchanger and its experimental verification. Appl Energ; 86:2005- 12.

[26] Oppelt, T., Riehl, I., Gross, U., 2010. Modelling of the borehole filling of double U-pipe heat exchangers. Geothermics ;39, 270-6.

[27] Esen, H., Inalli, M., 2009. Modelling of a vertical ground coupled heat pump system by using artificial neural networks. Expert Systems with Applications ;36,10229-38.

[28] Montagud, C., Corberán, JM., Ruiz-Calvo, F, 2013. Experimental and modeling analysis of a ground source heat pump system. Appl Energ ;109, 328-36.

[29] Ruiz Calvo, F., 2015. Análisis y modelado de una instalación geotérmica para clima- tización de un conjunto de oficinas. PhD thesis, Universitat Politècnica de València.

[30] Ruiz-Calvo, F., De Rosa, M., Acuña, J., Corberán, JM., Montagud, C., 2015. Experimental validation of a short-term Borehole-to-Ground (B2G) dynamic model. Appl Energ;140, 210-23.

[31] De Rosa, M., Ruiz-Calvo, F., Corberán, JM., Montagud, C., Tagliafico, LA., 2015. A novel TRNSYS type for short-term borehole heat exchanger simulation: B2G model. Energy Conversion and Management;100, 347-57.

[32] Eskilson, P.,1986. Superposition Borehole Model. Manual for Computer Code. Dept. of Mathematical Physics, Lund Institute of Technology, Lund, Sweden.

[33] Liu, X., 2005. Development and experimental validation of simulation of hydronic snow melting systems for bridges, Tesis Doctoral, Oklahoma State University.

[34] GeoCool project (EU 5th Framework Programme, NNE5-2001-00847), http://cordis.europa.eu/search/result_en?q=geocool.

[35] Montagud, C., Corberán, JM., Montero, Á., Urchueguía, JF., 2011. Analysis of the energy performance of a Ground Source Heat Pump system after five years of operation. Energ Buildings;43, 3618-26.

[36] Ruiz-Calvo, F., Montagud, C., 2014. Reference data sets for validating GSHP system mod- els and analyzing performance parameters based on a five-year operation period. Geothermics;51, 417-428.

[37] Ground-Med: Advanced ground source heat pump systems for heating and cooling in Mediterranean climate, http://www.groundmed.eu/.

[38] Monzó, P., Ruiz-Calvo, F., Acuna, J., Montagud, C., 2014. Experimental Validation of a Numerical Model for the Thermal Response of a Borehole Field, in: ASHRAE Transactions 2014. 
[39] Monzó, P., Mogensen, P., Acuña, J., Ruiz-Calvo, F., Montagud, C., 2015. A novel numer- ical approach for imposing a temperature boundary condition at the borehole wall in borehole fields. Geothermics;56, 35-44. 
Tables:

\begin{tabular}{|c|c|c|}
\hline Node & Balance equation & $\begin{array}{l}\text { N. } \\
\text { Eq }\end{array}$ \\
\hline \multirow[t]{2}{*}{$\begin{array}{l}\text { Fluid } \\
\text { Nodes }\end{array}$} & $\frac{\partial T_{1}(z)}{\partial t}=-v \cdot \frac{\partial T_{1}(z)}{\partial t}-\frac{1}{C_{f}}\left(\frac{T_{1}(z)-T_{b 1}(z)}{R_{b 1}}+\frac{T_{1}(z)-T_{2}(z)}{R_{p p}}\right)$ & (1) \\
\hline & $\frac{\partial T_{2}(z)}{\partial t}=-v \cdot \frac{\partial T_{2}(z)}{\partial t}-\frac{1}{C_{f}}\left(\frac{T_{2}(z)-T_{b 2}(z)}{R_{b 2}}-\frac{T_{1}(z)-T_{2}(z)}{R_{p p}}\right)$ & (2) \\
\hline \multirow[t]{2}{*}{$\begin{array}{l}\text { Borehole } \\
\text { Nodes }\end{array}$} & $C_{b 1} \frac{\partial T_{b 1}(z)}{\partial t}=\frac{T_{1}(z)-T_{b 1}(z)}{R_{b 1}}+\frac{T_{b 1}(z)-T_{b 2}(z)}{R_{b b}}-\frac{T_{b 1}(z)-T_{g}(z)}{R_{g}}$ & (3) \\
\hline & $C_{b 2} \frac{\partial T_{b 2}(z)}{\partial t}=\frac{T_{2}(z)-T_{b 2}(z)}{R_{b 2}}-\frac{T_{b 1}(z)-T_{b 2}(z)}{R_{b b}}-\frac{T_{b 2}(z)-T_{g}(z)}{R_{g}}$ & (4) \\
\hline $\begin{array}{l}\text { Ground } \\
\text { Node }\end{array}$ & $C_{g} \frac{\partial T_{g}(z)}{\partial t}=\frac{T_{b 1}(z)-T_{g}(z)}{R_{g}}+\frac{T_{b 2}(z)-T_{g}(z)}{R_{g}}$ & (5) \\
\hline
\end{tabular}

Table 1: B2G energy balance equations [30]. 


\begin{tabular}{|l|l|l|}
\hline $\begin{array}{l}\text { Experimental } \\
\text { measurement }\end{array}$ & Type of sensor used & Accuracy \\
\hline Temperature & Four wire PT100 & $\pm 0.1 \mathrm{~K}$ \\
\hline Water flow rate & $\begin{array}{l}\text { Coriolis flow meter, Danfoss, model massflo } \\
\text { MASS 6000 }\end{array}$ & $<0.1 \%$. \\
\hline Power consumption & $\begin{array}{l}\text { Multifunctional power meters by Gossen } \\
\text { Metrawatt, model A2000 }\end{array}$ & $\begin{array}{l} \pm 0.5 \% \text { of the } \\
\text { nominal value }\end{array}$ \\
\hline
\end{tabular}

Table 2: Type of sensors installed at Geocool plant and their uncertainties. 


\begin{tabular}{|c|c|}
\hline Geometrical aspect & Value \\
\hline$I / H$ & 0.074 \\
\hline$r_{b} / H$ & 0.0016 \\
\hline$B / H$ & 0.063 \\
\hline
\end{tabular}

Table 3: Geometrical aspect ratios - UPV site 


\begin{tabular}{|c|c|c|}
\hline \multicolumn{3}{|c|}{ Thermophysical properties } \\
\hline Ground thermal conductivity & $k_{\mathrm{g}}$ & $2.09 W \mathrm{~m}^{-1} \mathrm{~K}^{-1}$ \\
\hline Grout thermal conductivity & $k_{\mathrm{b}}$ & $2.09 W m^{-1} K^{-1}$ \\
\hline Ground volumetric thermal capacitance & $C_{g}$ & $3200 \mathrm{~kJ} \mathrm{~m}^{-3} \mathrm{~K}^{-1}$ \\
\hline Grout volumetric thermal capacitance & $c_{b}$ & $3200 \mathrm{~kJ} \mathrm{~m}^{-3} \mathrm{~K}^{-1}$ \\
\hline Ground thermal diffusivity & $\alpha_{\mathrm{g}}$ & $0.002351 m^{2} h^{-1}$ \\
\hline \multicolumn{3}{|c|}{ Geometrical characteristics } \\
\hline Borehole diameter & $D_{\mathrm{b}}$ & $150 \mathrm{~mm}$ \\
\hline External U-pipe diameter & $D_{\mathrm{p}, \mathrm{e}}$ & $32 \mathrm{~mm}$ \\
\hline Internal U-pipe diameter & $D_{\mathrm{p}, \mathrm{i}}$ & $25.4 \mathrm{~mm}$ \\
\hline Shank spacing (center-to-center) & W & $70 \mathrm{~mm}$ \\
\hline Depth & $\mathrm{L}$ & 50 \\
\hline \multicolumn{3}{|c|}{ Model parameters } \\
\hline Number of nodes & $\mathrm{n}$ & $150-$ \\
\hline Borehole node thermal capacitance & $C_{\mathrm{b} 1}-C_{\mathrm{b} 2}$ & $17.56 J K^{-1}$ \\
\hline Ground node thermal capacitance & $\mathrm{C}_{\mathrm{g}}$ & $1200 J K^{-1}$ \\
\hline Borehole conductive thermal resistance & $R_{\mathrm{b} 1}-R_{\mathrm{b} 2}$ & $0.2738 K^{-1}$ \\
\hline Pipe to pipe thermal resistance & $R_{\mathrm{pp}}$ & $0.8525 K^{-1}$ \\
\hline Borehole to borehole thermal resistance & $R_{\mathrm{bb}}$ & $0.4257 K^{-1}$ \\
\hline Borehole to ground thermal resistance & $R_{\mathrm{g}}$ & $0.2772 K W^{-1}$ \\
\hline Equivalent pipes diameter & $D_{\text {eq }}$ & $45 \mathrm{~mm}$ \\
\hline Borehole node position & $D_{\mathrm{x}}$ & $150 \mathrm{~mm}$ \\
\hline Ground radial penetration diameter & $D_{\mathrm{gp}}$ & $860 \mathrm{~mm}$ \\
\hline Ground nodes position & $D_{1}$ & $\mathrm{~mm}$ \\
\hline
\end{tabular}

Table 4: Main parameters adopted in the present work. 


\begin{tabular}{|c|c|c|c|c|}
\hline \multicolumn{5}{|c|}{ Maximum absolute Error (K) } \\
\hline$k_{a}$ & 1 & 5 & 10 & 20 \\
\hline 5 & 0.45 & 0.08 & 0.04 & 0.03 \\
\hline 10 & 0.54 & 0.13 & 0.13 & 0.02 \\
\hline 20 & 0.59 & 0.13 & 0.06 & 0.03 \\
\hline 50 & 0.76 & 0.24 & 0.14 & 0.06 \\
\hline 100 & 1.06 & 0.58 & 0.45 & 0.31 \\
\hline \multicolumn{5}{|c|}{ Number of Blocks } \\
\hline & 1 & 5 & 10 & 20 \\
\hline & & & & \\
\hline 5 & 16 & 27 & 39 & 65 \\
\hline 10 & 22 & 30 & 47 & 76 \\
\hline 20 & 37 & 41 & 45 & 77 \\
\hline 50 & 56 & 60 & 65 & 74 \\
\hline 100 & 102 & 106 & 11 & 121 \\
\hline
\end{tabular}

Table 5: Maximum absolute error $(\mathrm{K})$ and maximum number of blocks needed for a simulation of one year depending on the values of the parameters $k_{a}$ and $m_{a}$ 
Figure 1
Click here to download high resolution image

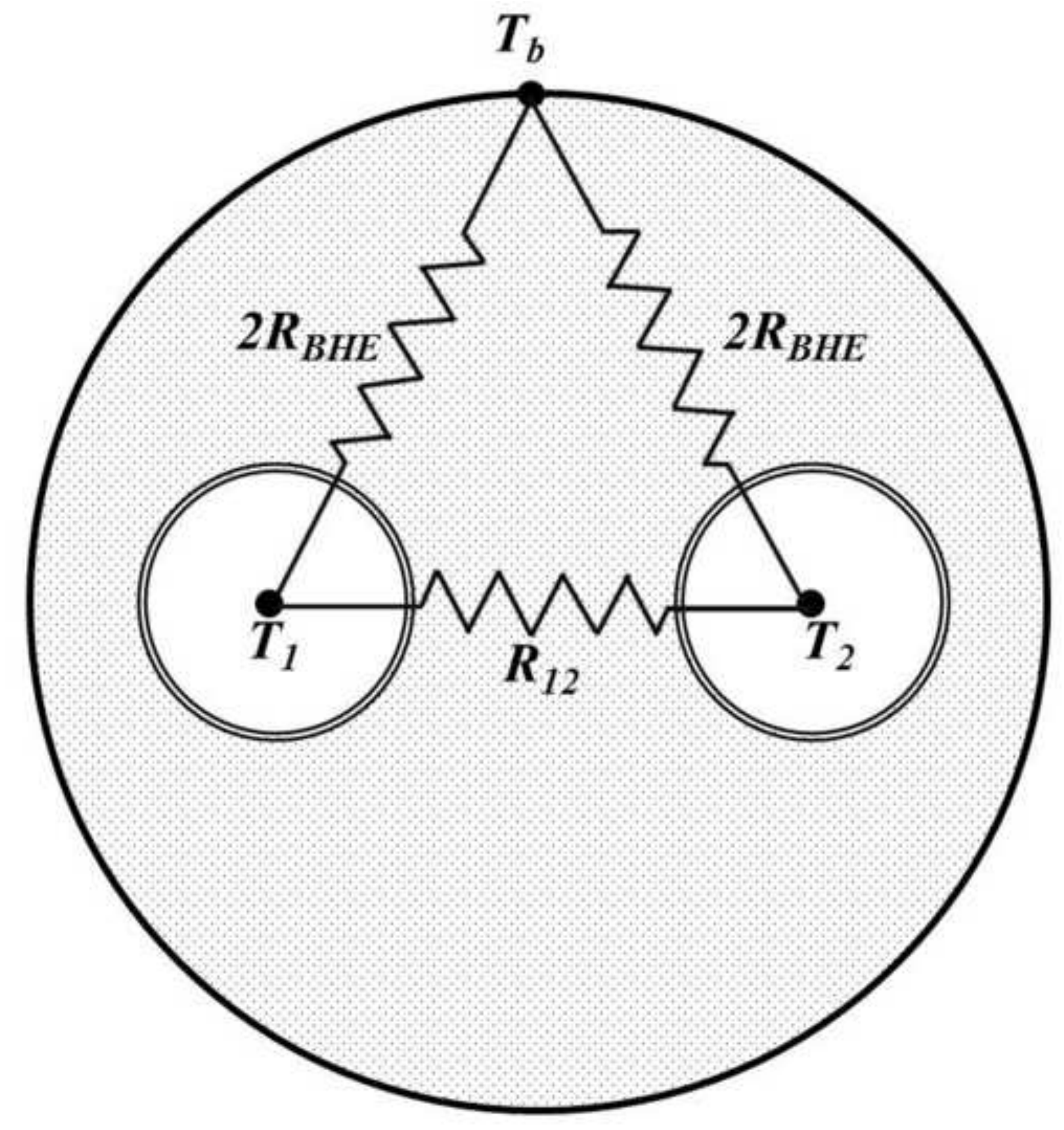


a)

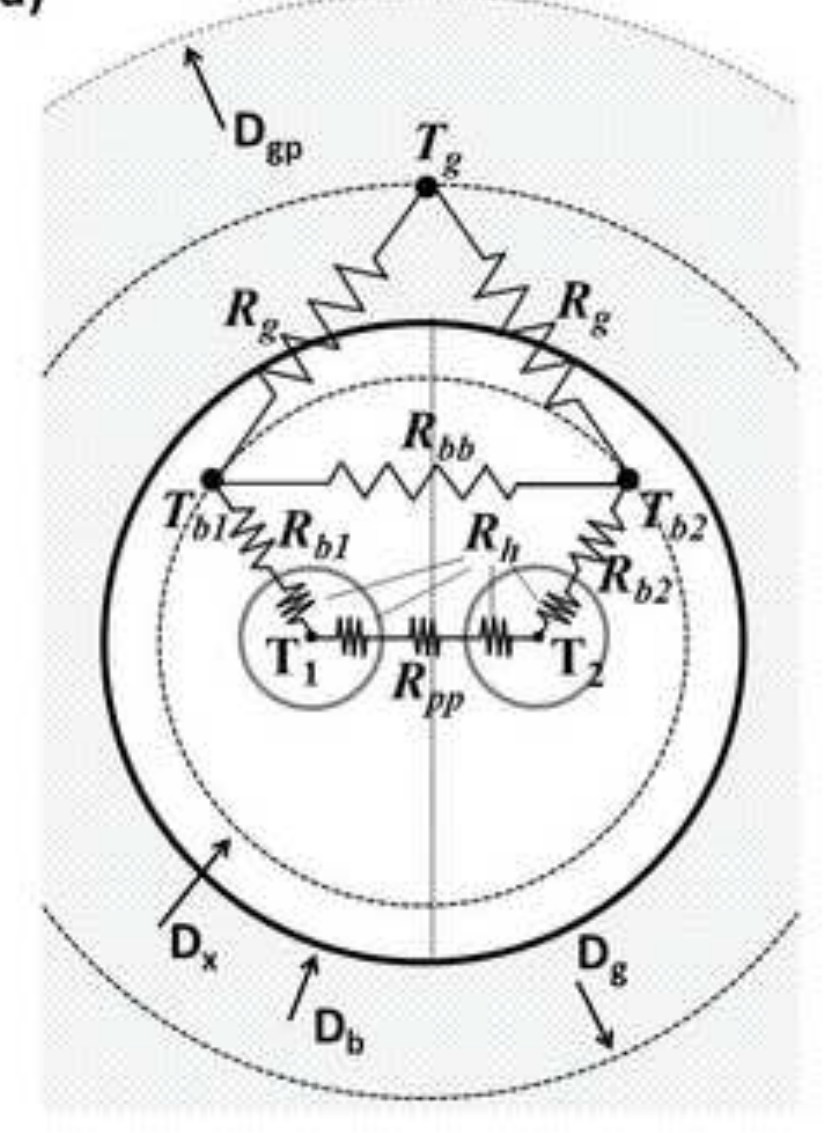

b)

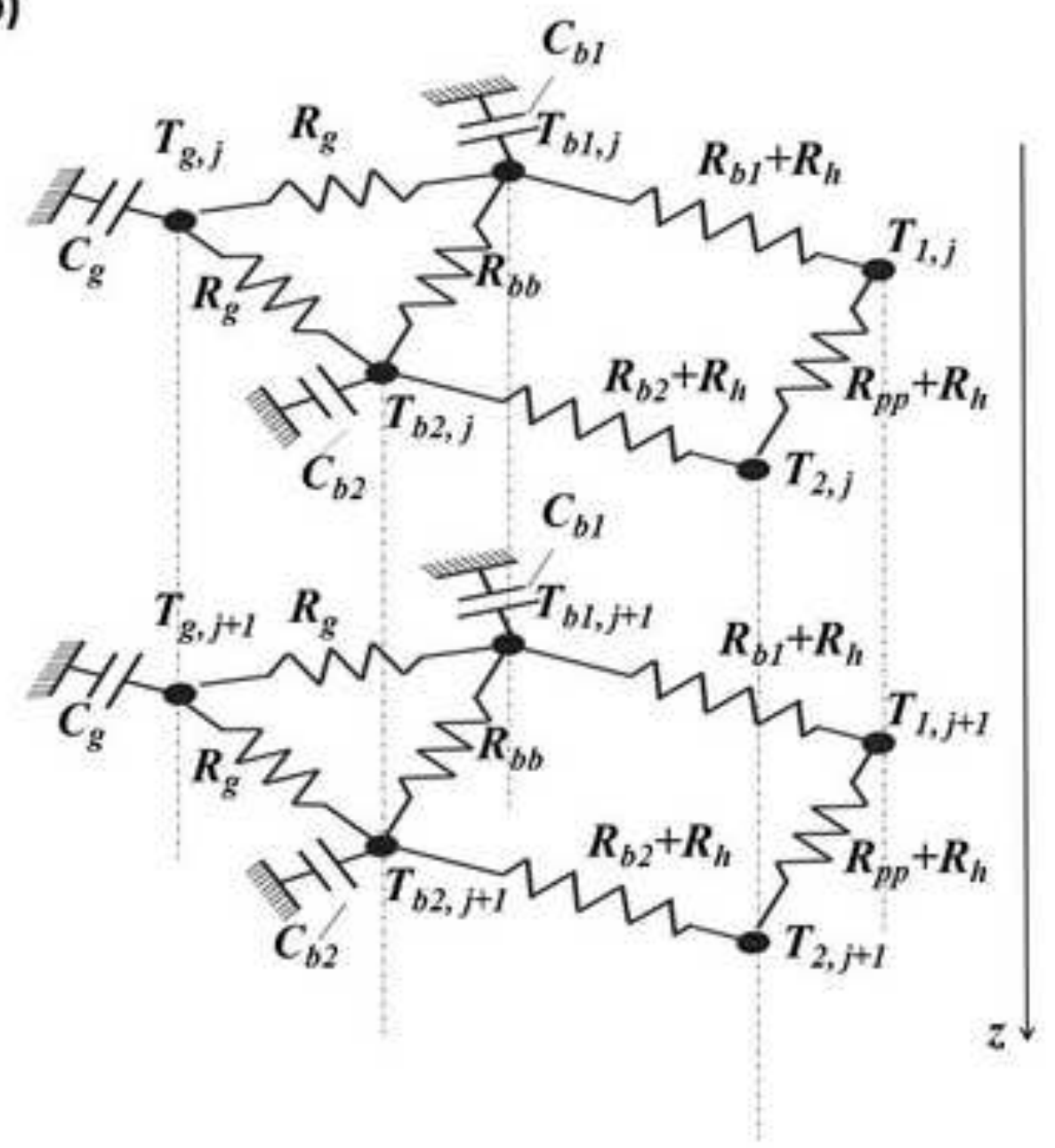




\section{Figure 3 reviewed}

Click here to download high resolution image

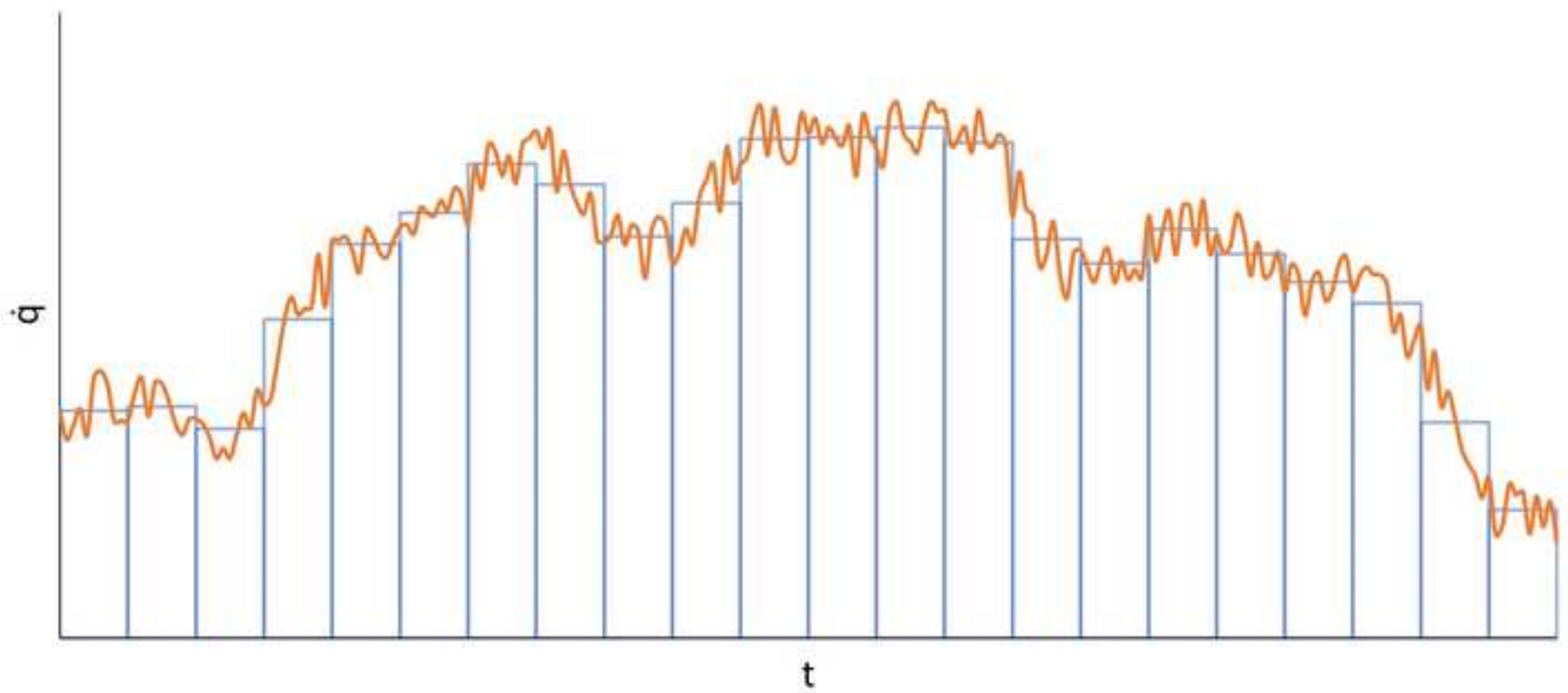


Click here to download high resolution image

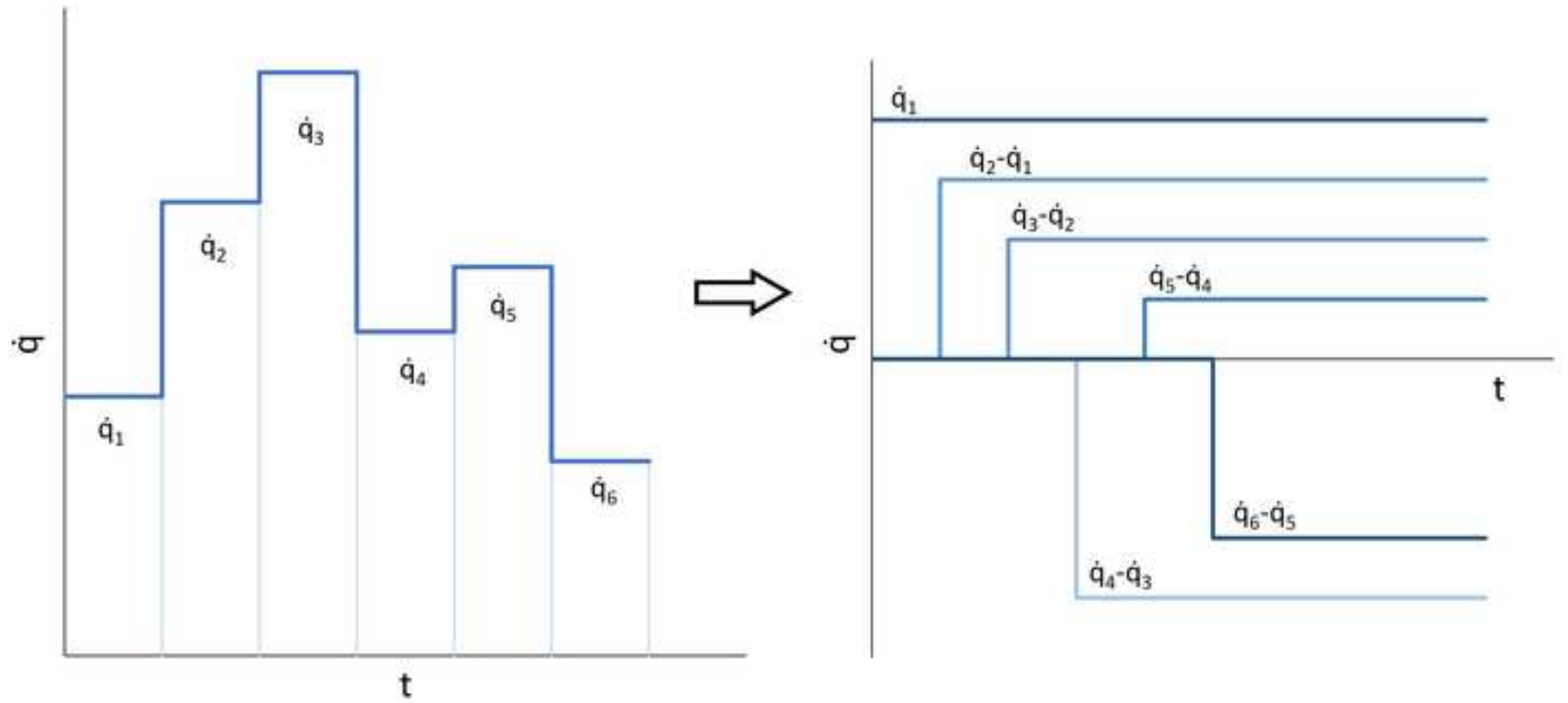


Click here to download high resolution image

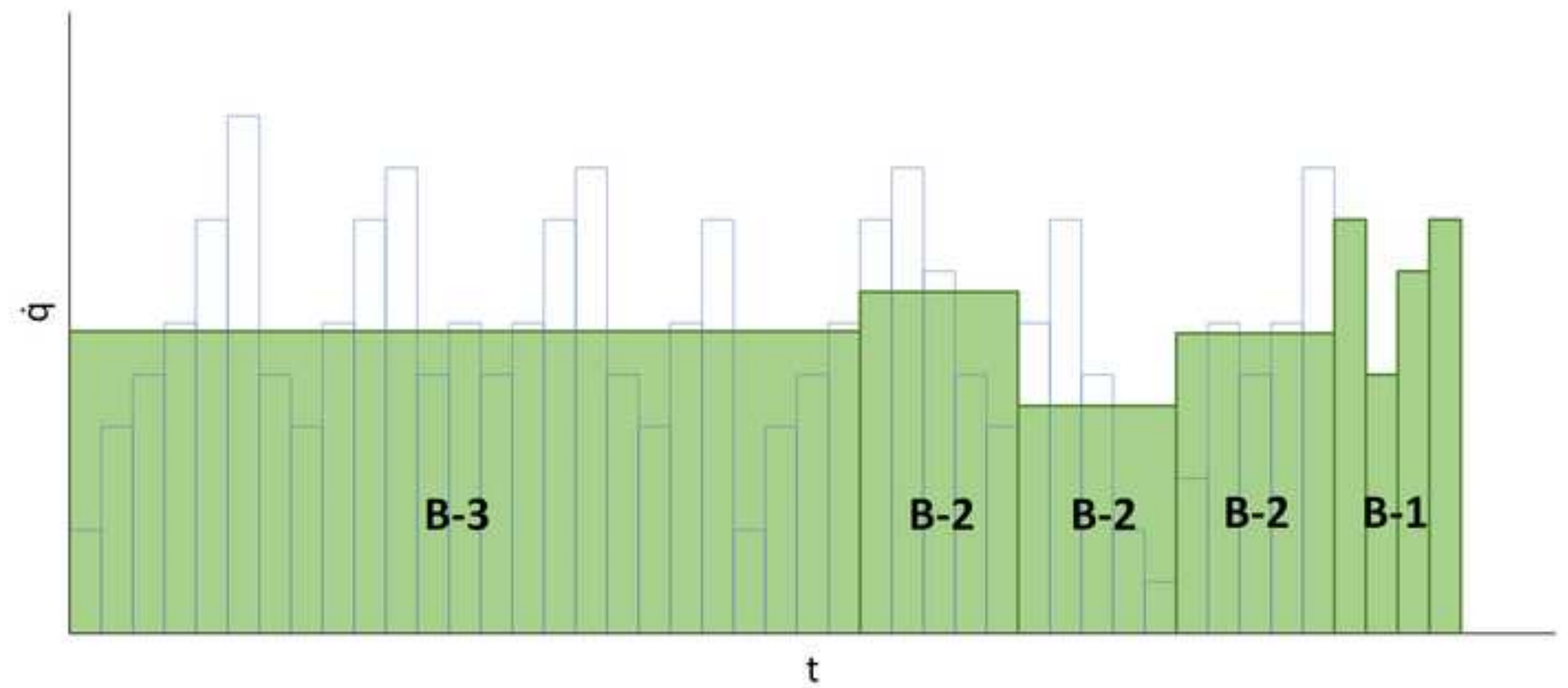


Figure 6

Click here to download high resolution image

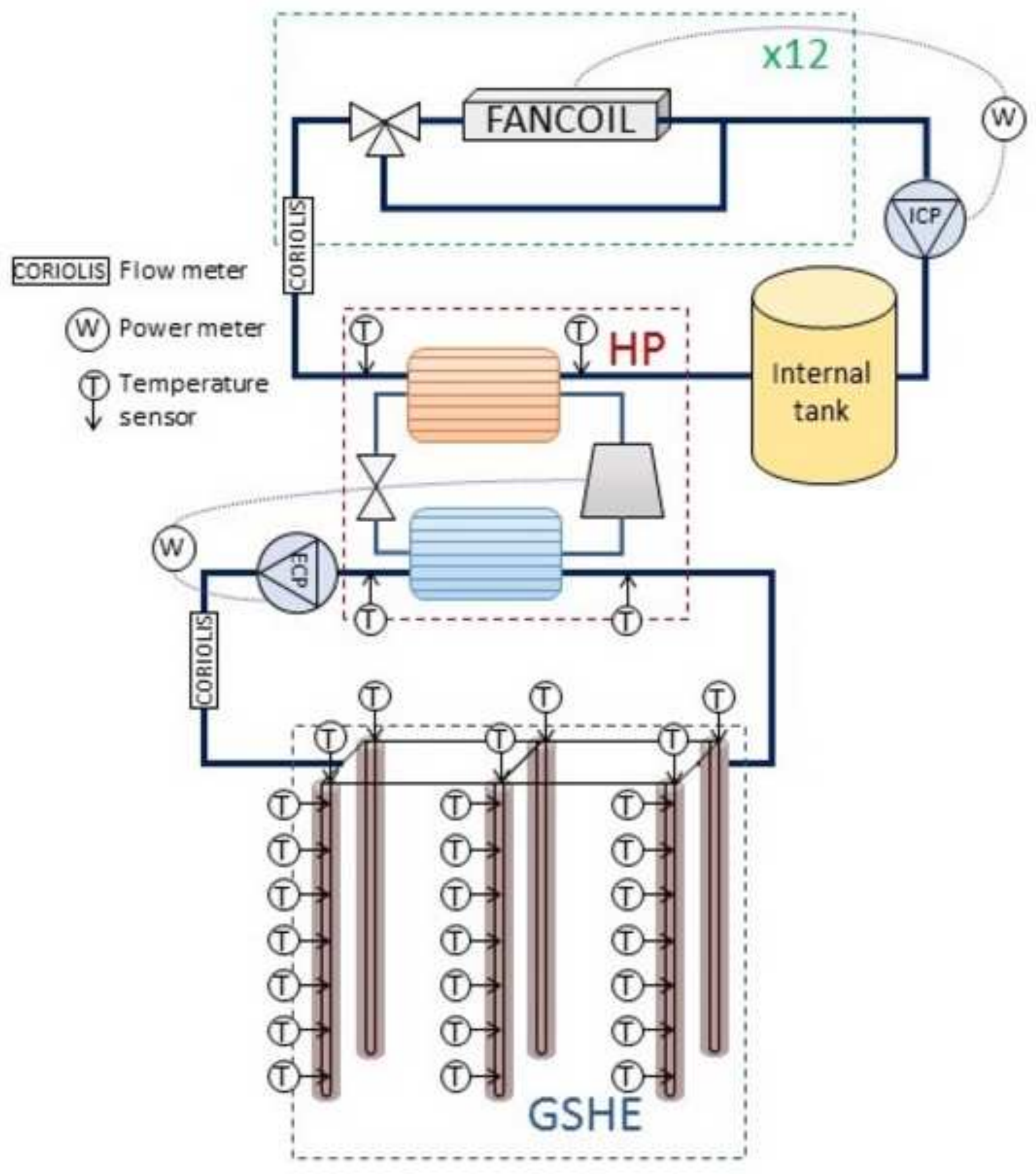




\section{reviewed}

Click here to download high resolution image

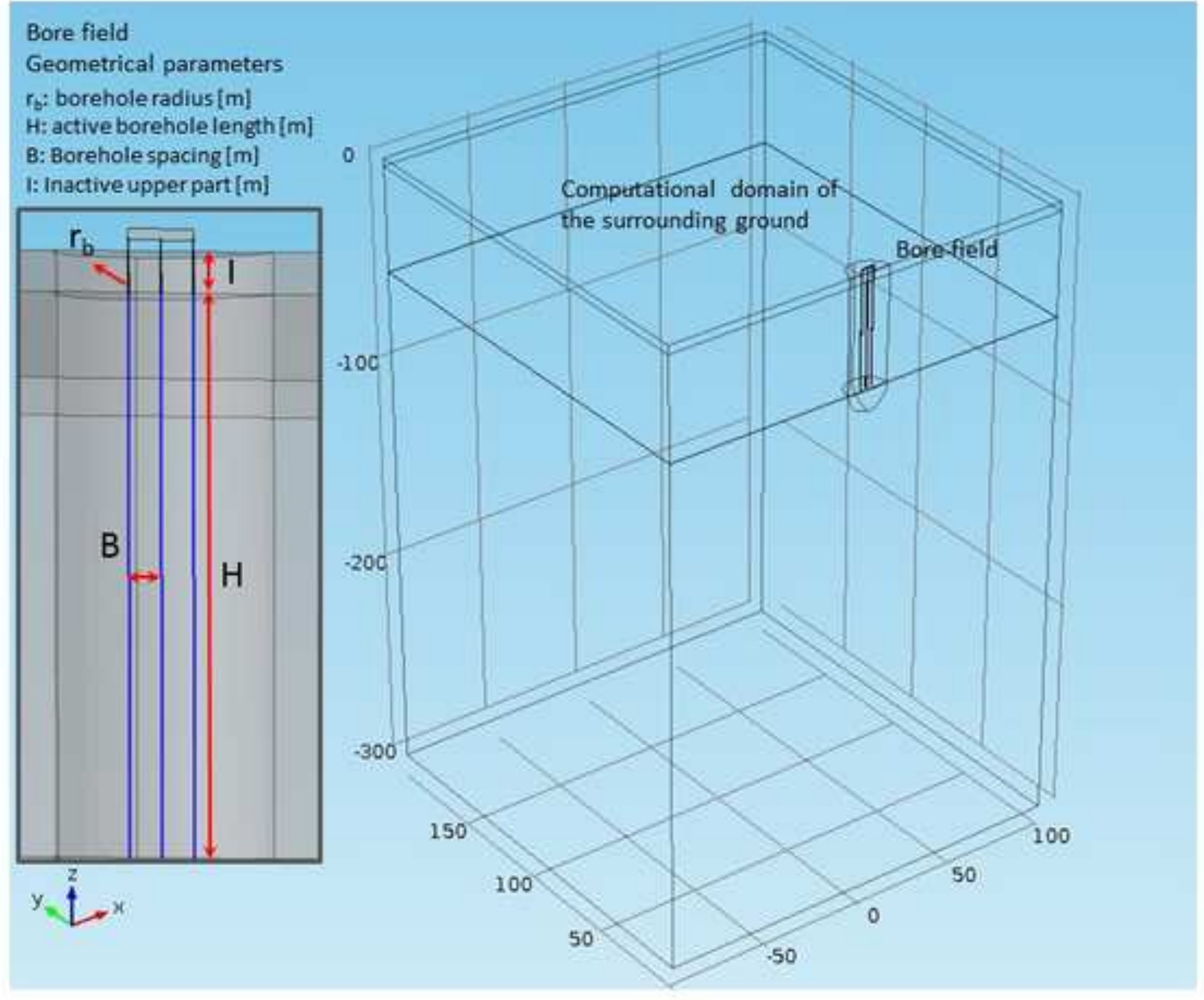


Click here to download high resolution image

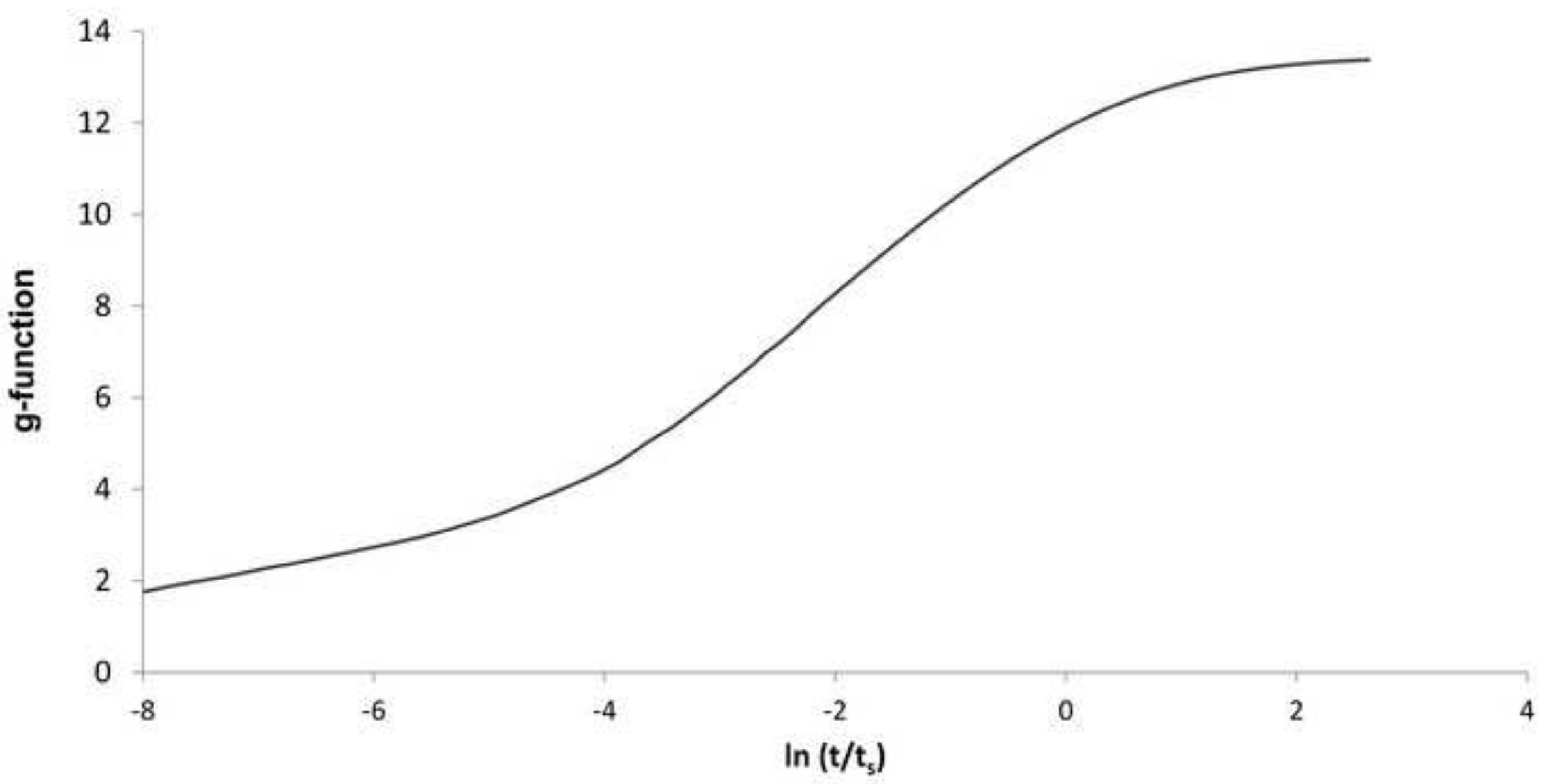


Click here to download high resolution image

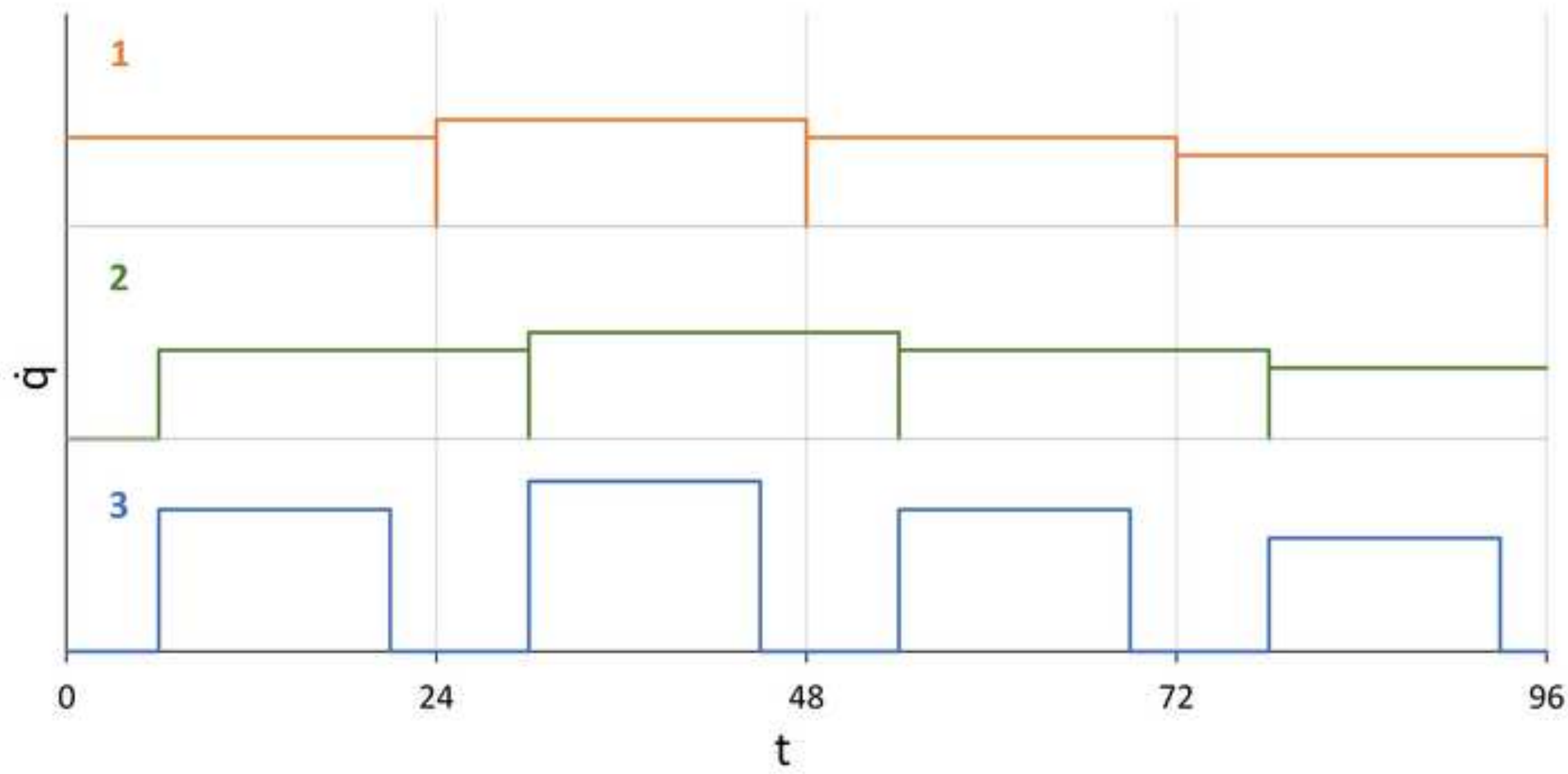


Figure 10

Click here to download high resolution image
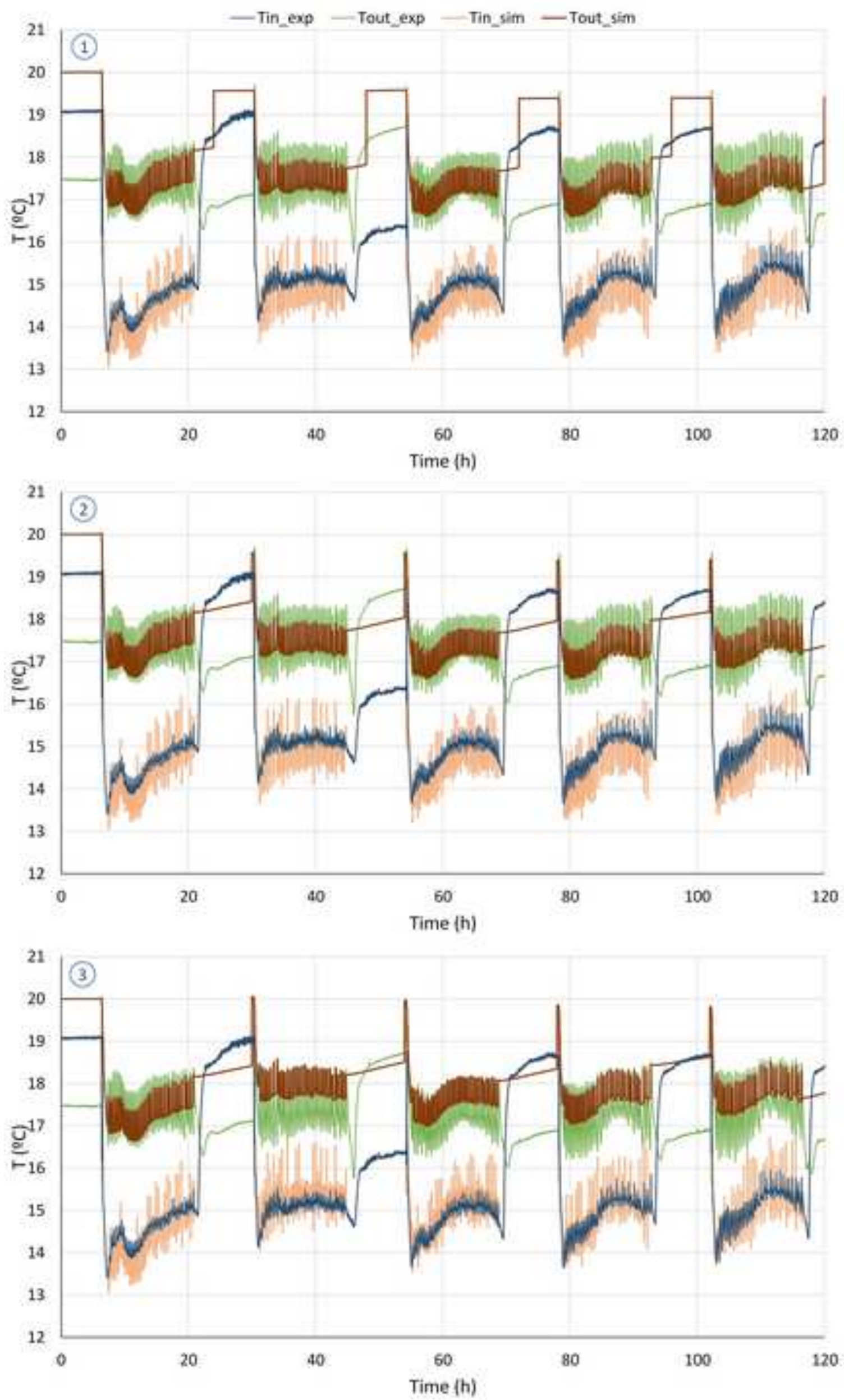


\section{Fure 11 reviewed}

Click here to download high resolution image

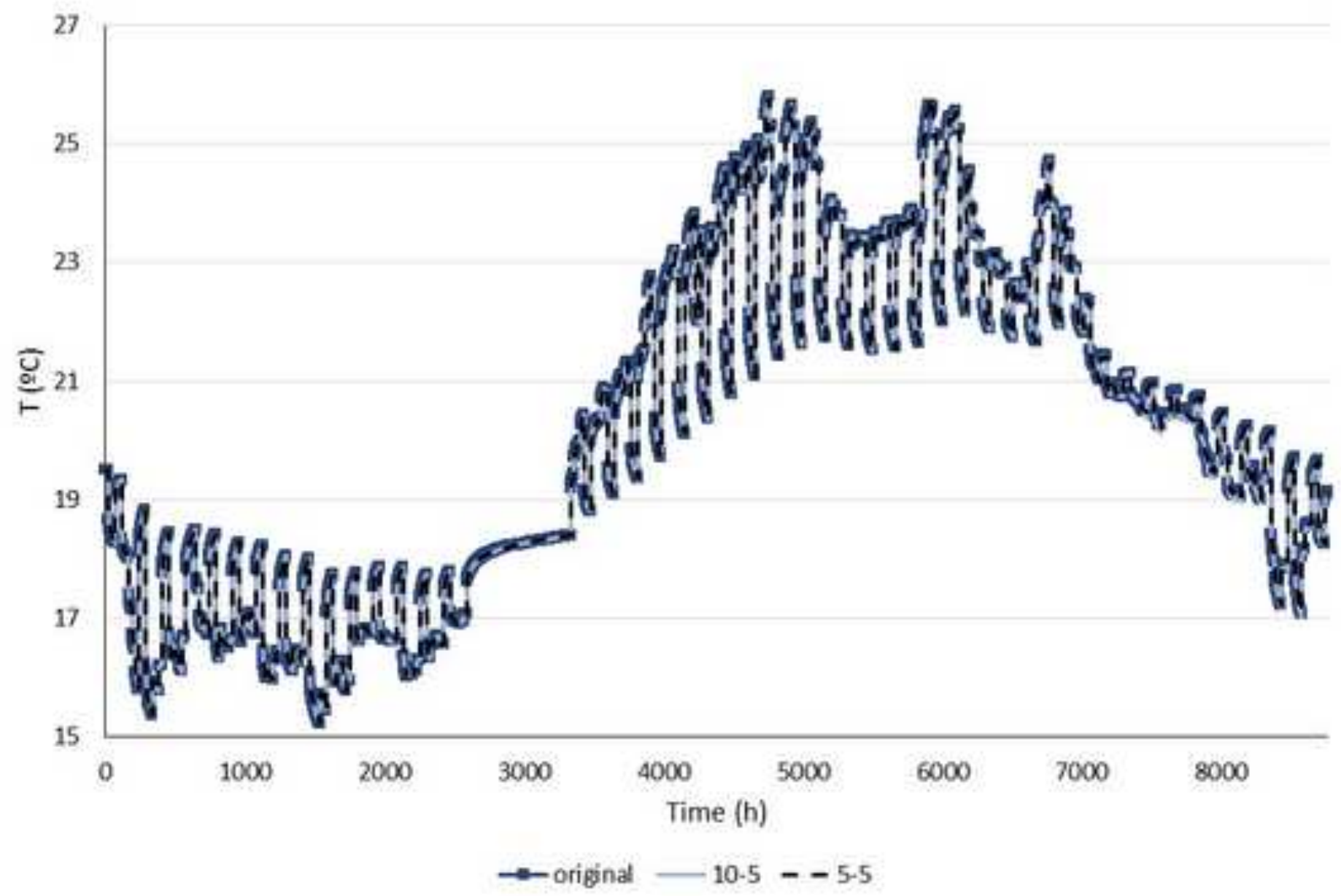


Click here to download high resolution image

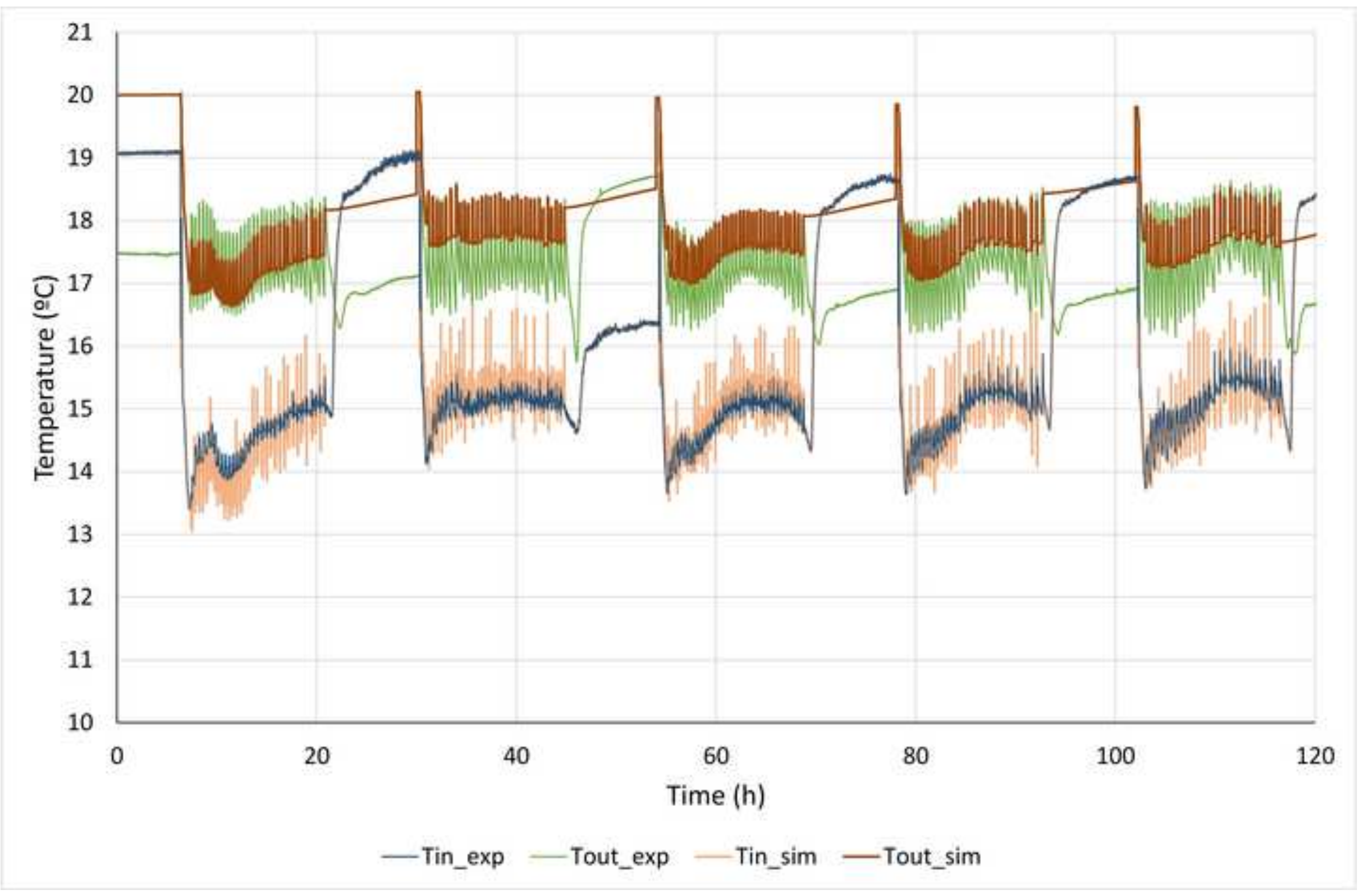


Figure 13

Click here to download high resolution image
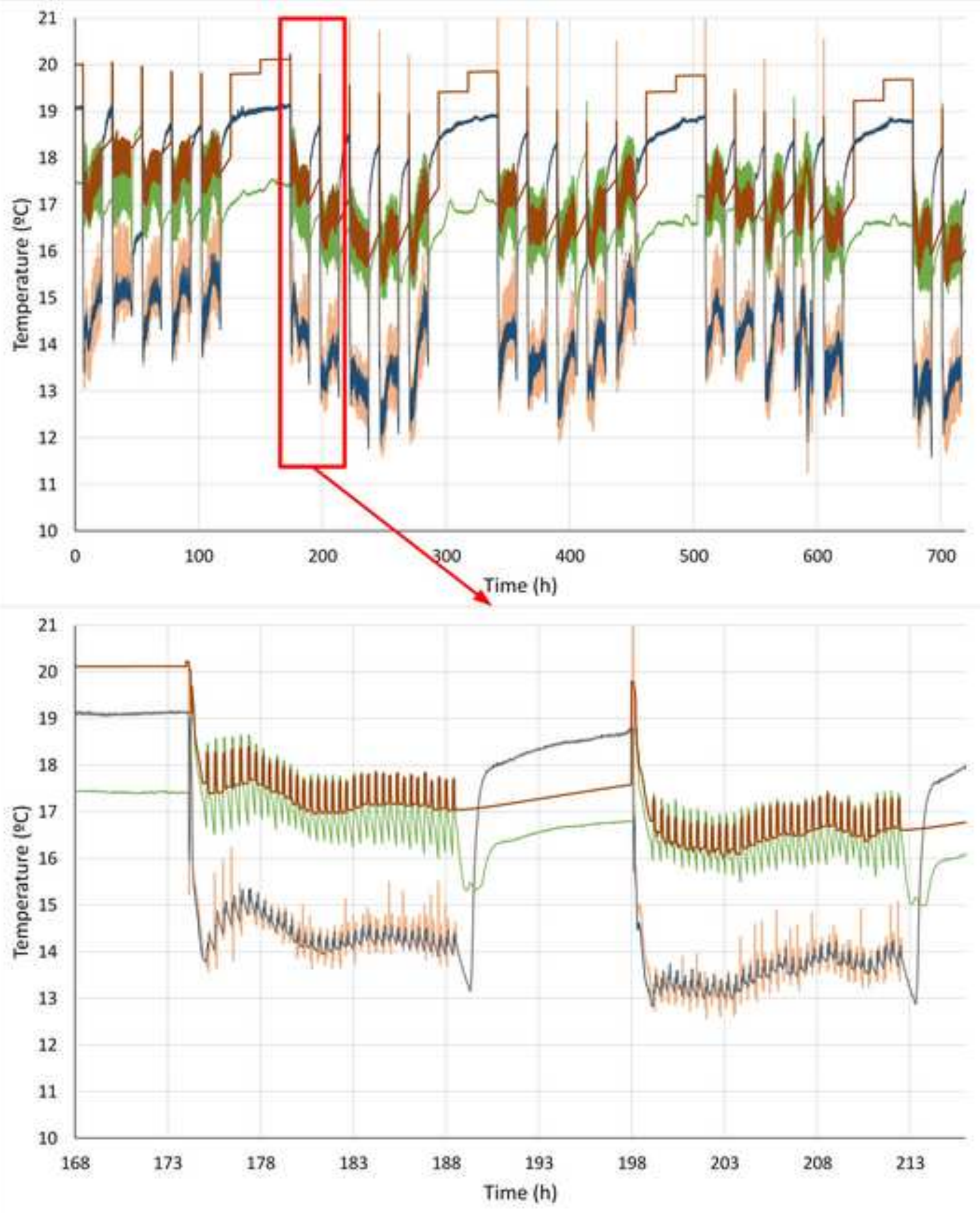

- Tin_exp - Tout_exp - Tin_sim - Tout_sim 
Click here to download high resolution image

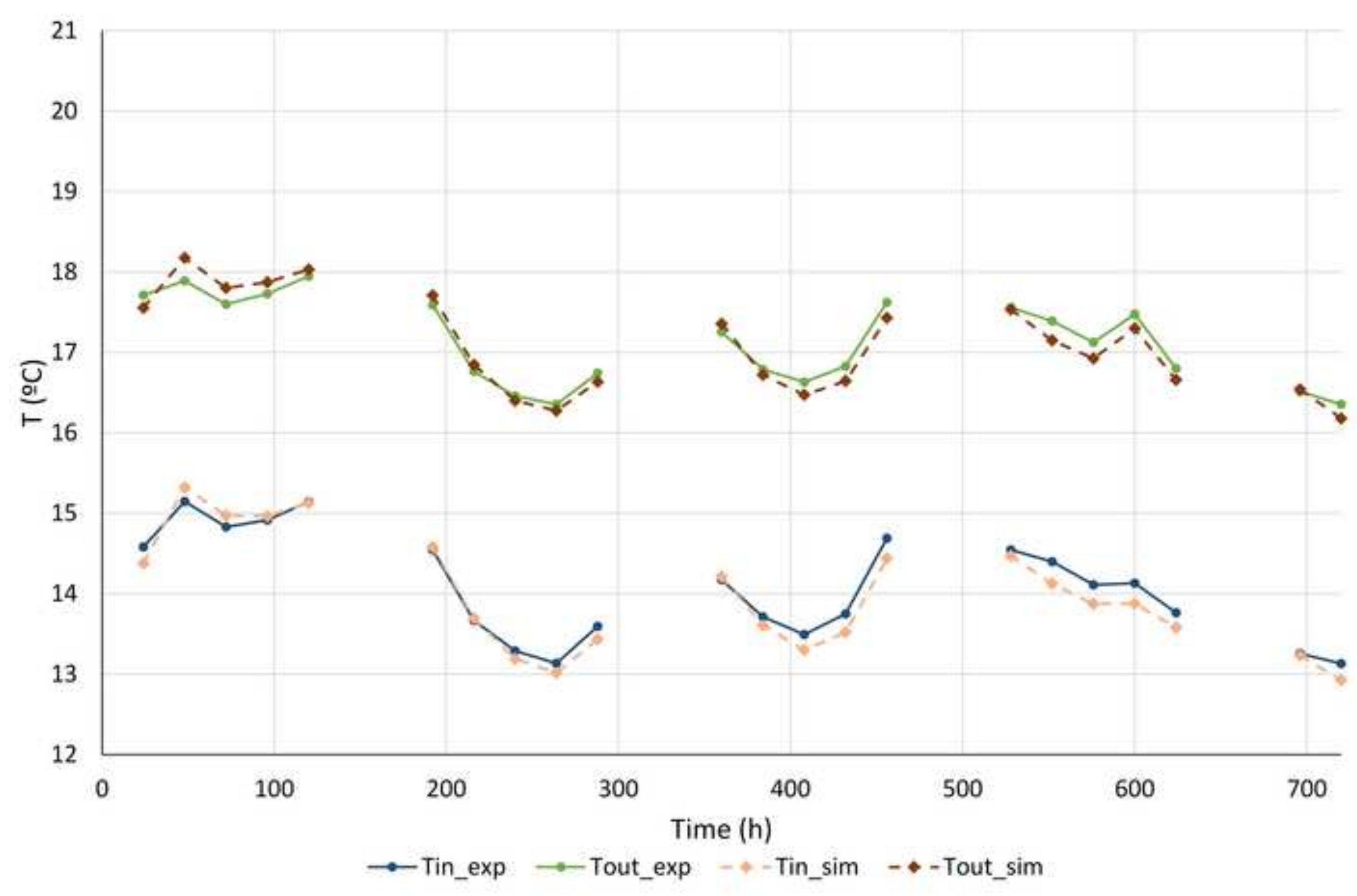

